\title{
A multi-sectoral approach to providing reproductive health information and services to young people in Western Kenya: The Kenya adolescent reproductive health project
}

\author{
Ian Askew \\ Population Council \\ Jane Chege \\ Population Council \\ Carolyne Njue \\ Population Council \\ Samson Radeny
}

Follow this and additional works at: https://knowledgecommons.popcouncil.org/departments_sbsr-rh

Part of the Family, Life Course, and Society Commons, International Public Health Commons, and the Maternal and Child Health Commons

How does access to this work benefit you? Let us know!

\section{Recommended Citation}

Askew, Ian, Jane Chege, Carolyne Njue, and Samson Radeny. 2004. "A multi-sectoral approach to providing reproductive health information and services to young people in Western Kenya: The Kenya adolescent reproductive health project," FRONTIERS Final Report. Washington, DC: Population Council. 
A Multi-Sectoral Approach to

Providing Reproductive Health

INFORMATION AND SERVICES

to Young People in Western Kenya:

Kenya Adolescent Reproductive Health Project

June 2004

Frontiers in Reproductive Health

Population Council

Ian Askew

Jane Chege

Carolyne Njue

Program for Appropriate Technology in Health (PATH)

Samson Radeny

Government of Kenya

Ministry of Health

Ministry of Education, Science and Technology

Ministry of Gender, Sport, Culture and Social Services

This study was funded by the United States Agency for International Development (USAID) under the terms of the Cooperative Agreement Number HRN-A-00-98-00012-00 and Population Council In-house project 580013042 and Subagreement with PATH AI99.91A. The opinions expressed herein are those of the authors and do not necessarily reflect the views of USAID. 


\section{ACKNOWLEDGEMENTS}

The authors would like to acknowledge and thank the following people who have all played a crucial role in developing and implementing this project. At the national level, Grace Kihindas, Melissa Mulimba, Dr. Mukumi Dr. Rupani, Dr. Kibaru, Dr. Godia and Dr. Solomon from the Division of Reproductive Health, Ministry of Health; Martha Gitonga, Margaret Odera and Elijah Mungai from the Ministry of Education, Science and Technology; and Anne Ambwere and Josephine Muriuki from the Department of Social Services, Ministry of Gender, Sports, Culture and Social Services, all played crucial roles in ensuring that the project was designed to meet the needs and organizational requirements of their individual ministries. At the provincial level, we would like to acknowledge the support and active involvement of Ernest Sagalla (Ministry of Health), Musungu Murakwa and Antony Kenya Khusa (Ministry of Education, Science and Technology).

Special mention must be made of Masibo Wamalwa, the Study Coordinator based in Kakamega. He worked tirelessly to ensure that the project activities were not only accepted by the communities after some initial concerns, but also that activities were implemented and coordinated according to plan and on schedule. If there is one person that the communities in Vihiga and Busia associate with this project it is Wamalwa, and the authors would like to recognize his outstanding contribution to the project's success.

The authors would like to acknowledge several other individuals for their important roles in the study. From PATH/Kenya, these include Michelle Folsom, Rikka Trangsrud and Irene Otieno. From FHI and the Population Council, Susan Adamchak, Nancy Williamson, Monica Wanjiru, Barbara Janowitz, Emily Wong, Stirling Cummings, Charlotte Warren and Isaac Lamba all contributed extensively to the study.

And finally, the project would not have been possible without the commitment, energy and time contributed by all the teachers, medical staff, Community Development Assistants, Peer Educators and community leaders who implemented the project activities. 


\section{EXECUTIVE SUMMARY}

Informing adolescents about appropriate and acceptable behaviours, and ways to protect themselves against unwanted and unprotected sex, has proved problematic in Kenya. Education programmes for in and out of school adolescents are lacking, there is controversy around providing services to sexually active adolescents, and a pervasive concern that sexuality education and contraceptive services leads to promiscuity. Unbiased and accurate information and services must be provided if adolescents are to delay becoming sexually active, to resist pressures to engage in non-consensual sex, and to protect themselves against unwanted pregnancies and infections if they do have sex. Moreover, strategies for providing such information and services need to be acceptable to the community and be sustainable over time.

In response to this situation, the Population Council's Frontiers in Reproductive Health Program and the Program for Appropriate Technology in Heath (PATH) Kenya office collaborated with three Government of Kenya ministries - the Ministry of Education, Science and Technology (MOEST), Ministry of Health (MOH), and the former Department of Social Services (now within the Ministry of Gender, Sports, Culture and Social Services (MOGSCSS) - to design and implement a multi-sectoral project with the following goals:

- To improve knowledge about reproductive health and encourage a responsible and healthy attitude towards sexuality among adolescents;

- To delay the onset of sexual activity among younger adolescents;

- To decrease risky behaviours among sexually active adolescents.

Three interventions were implemented and evaluated in two of the eight districts in Western Province. The intervention implemented by the MOGSCSS dealt with the sensitivity of the issue by having its Community Development Assistants (CDAs) work with community leaders and peer educators to create a supportive environment within which educational and service delivery activities could be implemented. The MOEST educated in-school adolescents about reproductive and sexual health through a life-skills and development curriculum taught by trained Guidance and Counselling teachers, supported by school-based peer educators. The $\mathrm{MOH}$ addressed the information and service needs, primarily of sexually active adolescents, by increasing access within health facilities through training staff, creating an adolescent-friendly room, and hosting peer educators.

The project was conducted in three phases over a 42-month period. Following a diagnostic study, a baseline population-based survey was completed. The interventions were developed and implemented over an 18-month period, during which the key activities and outputs were recorded on standard reporting forms and entered into a computerised management information system (MIS), and the costs calculated through collecting and analysing relevant direct and indirect costs. An endline population-based survey was then undertaken to measure changes in knowledge, attitudes and behaviour, after which the study findings were disseminated at district, provincial, national and international levels. The study used a quasiexperimental design with six 'Locations' (the lowest administrative level of government) selected, three each in Vihiga and Busia districts, to be the 'experimental' and 'control' sites. The three locations in each district were then randomly allocated to being site $\mathrm{A}$ or $\mathrm{B}$ or $\mathrm{C}$. The community-based and health facility-based interventions were introduced in the ' $A$ ' Locations, and all three interventions were introduced into the ' $\mathrm{B}$ ' Locations so that the additional effect of educating school children and sensitising parents could be assessed. The baseline and endline surveys were also undertaken in the control Location, ' $C$ '. 
Approximately 1,000 boys, 2,700 girls, 350 fathers and 830 mothers were interviewed in each survey.

The key findings are as follows. First, the three ministries successfully implemented the interventions, so that a significant proportion of adolescents and parents participated in one or more activities. The health facility-based activities were not widely used, and given that the cost of this intervention was 1.5 times as much as the community-based intervention, it is questionable whether investing in making clinics youth-friendly is a cost-effective strategy in this setting. The peer educator models were successful in reaching adolescents, especially with information although their sustainability is likely to be limited.

Parent-child communication increased significantly in site A for all adolescents except the younger boys, but whether this was because site A had two CDAs and more peer educators than site B, or because the school-based activities in site B encouraged adolescents to talk more with their teachers than their parents, is not clear. The school-based intervention raised awareness of basic sexual and reproductive health functions among all adolescents except older boys. Adolescents who participated in the community-based or school-based interventions significantly improved awareness of contraceptives, although as knowledge of some specific methods increased in all three sites, it seems that the interventions did not have any additional effect. Although knowledge of specific STIs was higher in both intervention sites than in the control site, none of the interventions improved either knowledge of how to use a condom or the fertile cycle in a woman.

Abstinence was well communicated through both community and school-based interventions. Using a condom for prevention was better known among girls and boys in site A and among girls in the control site, but not among all adolescents in site B. This suggests that the schoolbased intervention may be diluting the effect of messages being communicated more widely in the districts and through the community-based activities.

Attitudes regarding premarital sex and childbearing in all sites remained conservative, indicating that the interventions not only did not challenge these, but also probably reinforced them. Approval of contraceptive and condom use improved in the control site and in site A, suggesting that the school-based intervention in site B has reinforced existing disapproval of contraceptive and condom use, countering wider trends towards approval.

The level of sexual activity among adolescents at the start of the study was not particularly high. The proportion ever having penetrative sex increased over time in site A and in the control site, but reduced among older boys in site B. This suggests some inhibitive effect by the combination of community and school-based interventions on a general trend towards increasing sexual activity. Indeed there was a significant delay in the age of first sex, particularly among girls and boys in site B and among those participating in the school-based interventions. Moreover, the majority of those who reported being sexually active had sex infrequently and with few partners - secondary abstinence remains the norm for the sexually active.

Reports of non-consensual first-time sex were high in the baseline survey, but there were significant decreases in these proportions by the endline survey, together with an increased likelihood of first having sex with a friend rather than someone else - these are encouraging indications of less dangerous practices. The proportions of sexually active adolescents using protection remained low after the interventions, although some improvements among boys at first sex and girls at last sex were found in site A (and also for girls participating in the school activities and those living in the control site). Protection was primarily through using a 
condom. Declines in reports of pregnancy among unmarried adolescents also support the possibility of a trend towards safer sexual behaviour, at least among girls.

In interpreting these findings it is important to highlight the dramatic changes that were occurring within Kenya during the time of this study. All three ministries independently developed initiatives, at both the provincial and national levels. For example, the 'Adolescent Reproductive Health and Development' Policy was developed over this period (and was launched in September 2003), the Ministry of Education launched a school-based HIV/AIDS education curriculum and campaign, and the Children's Act was passed in 2001.

Some changes occurred in the control site that may reflect these wider activities: increased awareness of specific contraceptive methods; knowledge that condom use and other behaviours can prevent HIV transmission; approval of condom use among boys; and increased condom use by girls. However, both intervention sites showed significant changes in many key indicators, which suggests the community-based and school-based activities have had additional impacts. Most importantly, these include: increasing the amount of information available and awareness of reproductive health issues; maintaining and strengthening attitudes favouring promotion of abstinence and fidelity, while also improving attitudes towards practising protected sex; and commencing a delay in sexual initiation (especially among those participating in the school-based activities) and encouraging safer sex practices (especially among girls, and among girls participating in the school-based activities).

In using these findings to inform programme planning, it is essential that each ministry pay close attention to the specific effects that each intervention was able, and just as importantly was not able, to achieve. Moreover, it is important that the costs of implementing each set of activities are considered in relation to what they have achieved so that only cost-effective activities are promoted for further replication. 


\section{BACKGROUND}

\section{Sexual and reproductive health among adolescents in Kenya}

The sexual and reproductive health of adolescents is a priority concern for Kenyans, not only because they represent about a quarter of the population, but also because they are the productive generation of the future. Unwanted early pregnancies and infection with STIs including HIV are two of the most serious reproductive heath outcomes of early and unprotected sex, but many other adverse outcomes (such as non-consensual sex, transactional sex and incest) are possible if adolescents are uninformed and misguided about their sexuality and about gender relations. The reality of life for adolescents in Kenya, and particularly the nature of their intimate relationships, is not well understood, leading to many misconceptions and stereotyping of how they think and behave. This makes it difficult for society as a whole, and for those responsible for adolescent-oriented programmes and services in particular, to understand adolescents' needs.

A recently completed analysis of data collected from adolescents about their sexual and reproductive health during the last decade provides a useful summary of the current status of adolescents' sexual behaviour and their reproductive health ${ }^{1}$. The study showed that there has been little discernible change in age at first sex for either boys or girls over time, with a median age at first sex among girls of 17.2 years and 16.0 years among boys. The majority of young male and female Kenyans have sex before marriage, and more than one premarital partner also appears to be the norm. There has, however, been a slight reduction recently in multiple partnerships reported by young women, but not among young men. It seems likely that people are acting on the "stick to one partner" message by reducing concurrent partnerships, but are continuing to engage in serial monogamy.

The biggest change observed over the last decade has been in condom use, which rose significantly among both young women and men, although particularly among young men. Ever use of condoms is highest among those who report multiple partners, but men and women who had sex with multiple partners in the previous year are not any more likely to have used a condom at last sex than those who are currently monogamous. In 1998, over 90 percent of sexually active women and 70 percent of sexually active men did not use a condom with their most recent non-marital partner.

There is little difference in sexual behaviour between urban and rural areas for both sexes, but there are differences by educational level. Women with some secondary education are less likely to undertake risky behaviour, but among men the level of education has virtually no effect on risky behaviour, except for increasing the use of condoms. The proportion of young Kenyans reporting unprotected sex with a non-marital partner has fallen by about 29 percent over the 1990s, with a larger decrease among men than among women, primarily through increased condom use. However, significant levels of risk remain, with about 15 percent of young men and women reporting some recent risky sex.

The fall in risky behaviour does not seem to be reflected in decreases in levels of HIV infection among young people, although this is to be expected. The higher the background level of HIV prevalence in a population, the smaller the amount of risky behaviour needed to

Kenya National AIDS/STD/TB/Leprosy Control Programme, National AIDS Control Council, The MEASURE Project. 2003. AIDS in Africa during the Nineties: Young People in Kenya. Carolina Population Center, University of North Carolina, Chapel Hill: USA. 
maintain incidence levels. HIV prevalence among adults in Kenya was estimated at 5 percent in 1990 and at 13 percent in 1998. Because of the rise in HIV prevalence in the general population, the risk of having sex with an HIV-infected person for young people in Kenya may actually have nearly doubled over the 1990s, even though absolute levels of risky behaviour fell.

\section{Meeting adolescents' sexual and reproductive health needs}

Informing adolescents about appropriate and acceptable behaviours, and ways to protect themselves against unwanted and unprotected sex, has proved problematic in Kenya. Parents, teachers, religious and community leaders, and health care providers are all expected to educate adolescents about personal and physical development, about relationships with each other, and about their roles in society, but their capacity to do so in a comfortable, open and unbiased way is clearly lacking. Consequently, many adolescents rely on the media and their friends and peers for sexual and reproductive health information, sources which are notoriously poor at providing accurate and appropriate information.

There is a lack of systematic education programmes for in and out of school adolescents, controversy and opposition to provision of services to adolescents, and a pervasive concern that provision of sexuality education and contraceptive services will lead to promiscuity. Highly placed policy makers and some religious organizations have actively opposed efforts to introduce Family Life Education (FLE) into schools; for example, an attempt by the National Council for Population and Development (NCPD) to formulate an explicit policy on FLE and reproductive health services for youth in 1996 was rejected by Parliament.

Adolescents who are sexually active face many barriers to accessing services, thereby reducing their ability to protect themselves. Guidelines for provision of reproductive health services, and especially contraceptives and condoms, to unmarried adolescents are deliberately ambiguous and open to conflicting interpretation. For example, the National Reproductive Health/Family Planning Policy Guidelines and Standards ${ }^{2}$ for service providers underline the importance of service providers making "comprehensive reproductive health information and counselling freely available for health reasons in good faith to adolescents and youth seeking this information." In addition, the guidelines stress: "Adolescents/youth who are sexually active, especially those who have been pregnant, have had a miscarriage or have been treated for STIs, need special attention in terms of reproductive health care. This includes appropriate treatment for existing conditions and counselling and provision of a full range of RH services."

This need for information and services for adolescents must be met if they are to delay becoming sexually active, to resist pressures to engage in non-consensual sex, and to protect themselves against unwanted pregnancies and infections when they do have sex. The strategies by which such information and services are provided to adolescents will need to be acceptable to even the most conservative groups in Kenyan society, and in a way that those providing the information and services feel comfortable. Moreover, to be able to reach the majority of adolescents and to be sustainable over time, these strategies will have to be developed and implemented by Government ministries that already have some responsibilities for serving adolescents. An 'Adolescent Reproductive Health and Development' policy was formally launched in October 2003, after three years of 
preparation, which, as stated by the Minister of Health, represents " a positive attempt to address issues of adolescent reproductive health as a national development concern and a clear manifestation of the Government's commitment to fulfil its obligations in this area". How best to implement this policy is a challenge facing the Government of Kenya.

\section{The Kenya Adolescent Reproductive Health Project}

To respond to this situation, the Population Council's Frontiers in Reproductive Health Program (FRONTIERS) and the Program for Appropriate Technology in Heath (PATH) Kenya office collaborated with three Government of Kenya ministries - the Ministry of Education, Science and Technology (MOEST), the Ministry of Health (MOH) and the former Department of Social Services (now within the Ministry of Gender, Sports, Culture and Social Services (MOGSCSS) - to design and implement a multi-sectoral project with the following ultimate goals:

- To improve knowledge about reproductive health and encourage a responsible and healthy attitude towards sexuality among adolescents;

- To delay the onset of sexual activity among younger adolescents;

- To decrease risky behaviours among sexually active adolescents.

To develop interventions that could be sustainable and replicable the project was designed to minimise the level of external resources needed through maximising the use of existing governmental structures, networks and systems. Consequently, the Kenya Adolescent Reproductive Health Project (or 'KARHP' as it has become known) was designed around the ways in which the three ministries currently operate at the district level, with each ministry taking the lead in implementing an intervention that addresses a particular aspect of adolescent reproductive and sexual health at the community level.

Extensive discussions with several experts in Kenya about potential sites to pilot test the intervention led to the study being implemented in Western Province, an area with above average levels of reproductive health problems among adolescents, relatively poor infrastructure and fairly densely populated rural areas. Two out of the eight districts in the province were chosen - Vihiga and Busia - to provide some variation in the characteristics of the study sites, although both districts are largely populated by the Luhya ethnic group, thus giving some degree of cultural homogeneity.

Technical assistance to all three ministries was provided by PATH and FRONTIERS. The interventions are described briefly below - more detailed descriptions of the preparation, development and implementation of the interventions can be found in Appendix A. In brief, three interventions were developed, each having specific objectives and each implemented by a different ministry. One intervention sought to address the sensitivity of the issue by working with communities to create a supportive environment within which the educational and service delivery activities could be implemented. A second intervention sought to meet adolescents' reproductive health information and service needs, primarily of sexually active adolescents, by increasing access within health facilities. A third intervention aimed to educate in-school adolescents about sexual and reproductive health within a framework of information about life-skills and development.

3 Ngilu, Charity. 2003. "Foreword" in Adolescent Reproductive Health and Development Policy, National Council for Population and Development, Nairobi: Kenya. 


\section{Creating a supportive environment for addressing adolescent reproductive health}

The Department of Social Services within the MOGSCSS was primarily responsible for this intervention through strategies of participatory community mobilization for engaging local civic and religious leaders and parents, and of reaching out of school youth with peer educators. The Ministry's Community Development Assistants (CDAs) ${ }^{4}$ undertook community mobilisation and peer educator supervision. A CDA is a full-time government worker based at the division level and responsible for community mobilisation for government development programmes.

PATH staff and consultants trained the CDAs in facilitative supervision, advocacy and community outreach using a compilation of materials including $\mathrm{MOH}$ supervision guidelines and excerpts from PATH's Communication for Social Change training manual. The intention was to work with four CDAs, one in each location, but in practice although both CDAs were active in sites A, the CDA in Nambale Location in site B was inactive.

The CDAs worked closely with 20 civic leaders and 80 religious leaders (including Protestants, Catholics and Muslims), training them in adolescent health and sexuality issues and encouraging them to raise these issues during both religious and community meetings. The CDAs also worked closely with trainers from the MOEST to train and supervise 120 outof-school peer educators (133 were recruited but 13 dropped out and were not replaced). An additional 83 'peer group leaders' (i.e. 203 peer educators in total) were recruited, many of them by the church leaders, to organize the outreach activities in which several peer educators would participate. The peer educators and peer group leaders were trained using a peer educator manual that was developed specifically as part of the study.

The CDAs were invited to hold sessions with parents and youth during religious meetings and community barazas (a formal meeting called by the local chief). They promoted their activities through drama, theatre, video shows and targeted public events. The training manual for peer educators focused on increasing knowledge, changing attitudes and providing skills to adopt safer sexual practices. It was also used to expose in and out of school adolescents to sexual and reproductive health issues.

\section{Meeting the information and service needs of sexually active adolescents}

The $\mathrm{MOH}$ was the lead ministry for this intervention, which was implemented primarily through strategies to improve the "friendliness" of public and private clinics towards adolescents seeking information or services. This was accomplished by training staff, creating designated spaces within the clinic for adolescents, and inviting the out-of-school peer educators who had been recruited and supervised by the CDAs to hold group and individual meetings in the designated rooms.

PATH staff worked with the managers of each health facility to improve the environment in which services were provided to adolescents. PATH staff and consultants trained service providers from four public and 12 private health facilities (out of 19 located in the study sites) on how to deliver youth-friendly reproductive health services. The selection criteria for 
the health providers to be trained included previous or current experience in providing services for adolescents; participation in youth development activities; willingness to perform volunteer work; age less than 40 years; flexibility and patience with young people; a positive, open attitude towards adolescents and their sexual health; and a good understanding of adolescent reproductive health. Thirty-eight providers (mostly female as there were very few male providers in these facilities) were identified and trained from the 16 facilities in the four study locations; these included one medical doctor, four clinical officers and 33 nurses.

\section{Educating in-school adolescents about physical development, behaviour and reproductive health}

The MOEST led the school-based intervention, which was implemented by training 74 Guidance and Counselling Teachers and 29 Head Teachers, establishing extra-curricula classes and recruiting, training and supervising 600 school-based peer educators to reach their schoolmates through activities such as theatre, debates, festivals and essay competitions. The manual for training school teachers focused on increasing their understanding of adolescent reproductive health and improving their skills in providing appropriate information and counselling to the youth in their schools. It was also used to guide teachers in how to expose in-school youth to sexual and reproductive health issues. The manual was organized to include 34 one-hour sessions that could be implemented easily within a school context. Some schools chose to conduct the sessions after regular school hours, while others incorporated the sessions into the official school schedule. The 34 sessions included a mix of reproductive health topics, such as human physiology, and life skills.

PATH and the MOEST trained six staff from the MOEST's divisional level as trainers, who then trained the Guidance and Counselling teachers. The Guidance and Counselling teachers then recruited, trained and supervised the peer educators within their schools. All six secondary schools in the two study locations where this intervention was implemented were included, plus 21 of the 25 primary schools (the remaining four schools were felt to be too small to include in the study), giving a total of 27 schools.

\section{EVALUATING THE INTERVENTIONS}

\section{Study design}

These three interventions were designed and implemented within the framework of an operations research study so that:

- The process and cost of designing and implementing the interventions could be fully documented;

- The outputs produced by each intervention could be systematically monitored; and

- The effectiveness and impact on adolescents and their parents could be rigorously evaluated.

The project was conducted in three phases over a 42-month period. First, a diagnostic study ${ }^{5}$ was undertaken to improve understanding of the study environment, the existing situation

PATH Kenya. 2000. A Report on the Diagnostic Study Conducted in Busia and Vihiga Districts in Western Kenya, PATH, Nairobi: Kenya. 
and the reproductive health needs of adolescents, and a baseline population-based survey ${ }^{6}$ completed to enable the impact of the interventions to be evaluated. Secondly, the interventions were developed and implemented over an 18-month period, during which the key activities and outputs were recorded on standard reporting forms and entered into a computerised management information system (MIS), and the costs calculated through collecting and analysing relevant direct and indirect costs. Thirdly, an endline populationbased survey was undertaken to measure changes in knowledge, attitudes and behaviour, after which the study findings were disseminated at district, provincial, national and international levels.

The study used a quasi-experimental design to determine the relative effectiveness and cost of the interventions. Six 'Locations' (the lowest administrative level of government in Kenya) were selected, three each in Vihiga and Busia districts, to be the 'experimental' and 'control' sites. The three locations in each district were randomly allocated to being site A or $\mathrm{B}$ or C. Two of the interventions were introduced in the Location allocated to site A in each district: one to create a supportive environment at the community level, and one to strengthen the health system's ability to meet the reproductive health information and service needs of adolescents. All three interventions were introduced into the location in each district allocated as site B, so that the additional effect of educating school children and sensitising parents on reproductive health issues and services could be assessed. In addition to these two experimental sites, the baseline and endline surveys were also undertaken in one 'control' Location in each district where none of the interventions were introduced (labelled 'Sites C').

\section{Selection of study sites}

Vihiga and Busia districts were selected on the basis that:

- Adolescent reproductive health was identified as a priority issue by the district authorities; and

- High incidences of sexually transmitted infections (STIs), including HIV/AIDS, teenage pregnancy, and school dropouts were thought to exist.

Within each district, a sub-sample of divisions were identified as being eligible for inclusion if they met the following criteria:

- Population size not less than 30,000;

- Existence of a network of community based health workers; and

- At least five public health facilities and any number of private health facilities.

Based on these criteria, six divisions in Vihiga and four in Busia were identified. One division from each district was then randomly selected for inclusion in the study - Sabatia Division in Vihiga and Butula Division in Busia.

Within each division, a sub-sample of locations were then identified as being eligible for inclusion if they met the criteria of:

$6 \quad$ Warren, C., J. Chege, I. Askew, S. Radeny and M. Folsom. 2001. Improving the Reproductive Health of Adolescents in Kenya: A Report on the Baseline Study on Two Districts in Western Kenya, Population Council, Nairobi: Kenya. 
- A population size of at least 15,000 ;

- At least one public health facility and any number of private health facilities;

- A minimum of ten primary and secondary schools.

Based on these criteria, six eligible locations were identified in Sabatia Division and four in Butula Division. Three locations in each division were then randomly selected, but were only included in the study if they were not contiguous with each other. West Maragoli, Wodanga, and Izava Locations were selected in Sabatia. In Butula Division, however, only two of the four locations (East Marachi and Central Marachi) fulfilled these criteria and were noncontiguous, and so a decision was made to select the third location (Nambale Location) that met these criteria from another eligible division (Nambale Division) in Busia District.

Finally, the three locations in each division were randomly assigned to being either site A, site $\mathrm{B}$ or site $\mathrm{C}$ where:

- Sites A: received the supportive environment and health facility interventions - West Maragoli Location in Sabatia Division (Vihiga District) and East Marachi Location in Butula Division (Busia District).

- Sites B: received the supportive environment, health facility and school-based components - Wodanga Location in Sabatia Division (Vihiga District) and Nambale Location in Nambale Division (Busia District).

- Sites C: were the control sites and did not receive any interventions - Izava Location in Sabatia Division (Vihiga District) and Central Marachi Location in Butula Division (Busia District).

From the most recent census data available ${ }^{7}$, the total population in the four experimental Locations was found to be 85,798 . Of this, approximately 52 percent $(44,538)$ are adolescents aged $10-19$ years.

Central Bureau of Statistics. 2001. The 1999 Population and Housing Census. Ministry of Finance and Planning: Nairobi, Kenya. 


\section{MAP OF STUdY SITES}

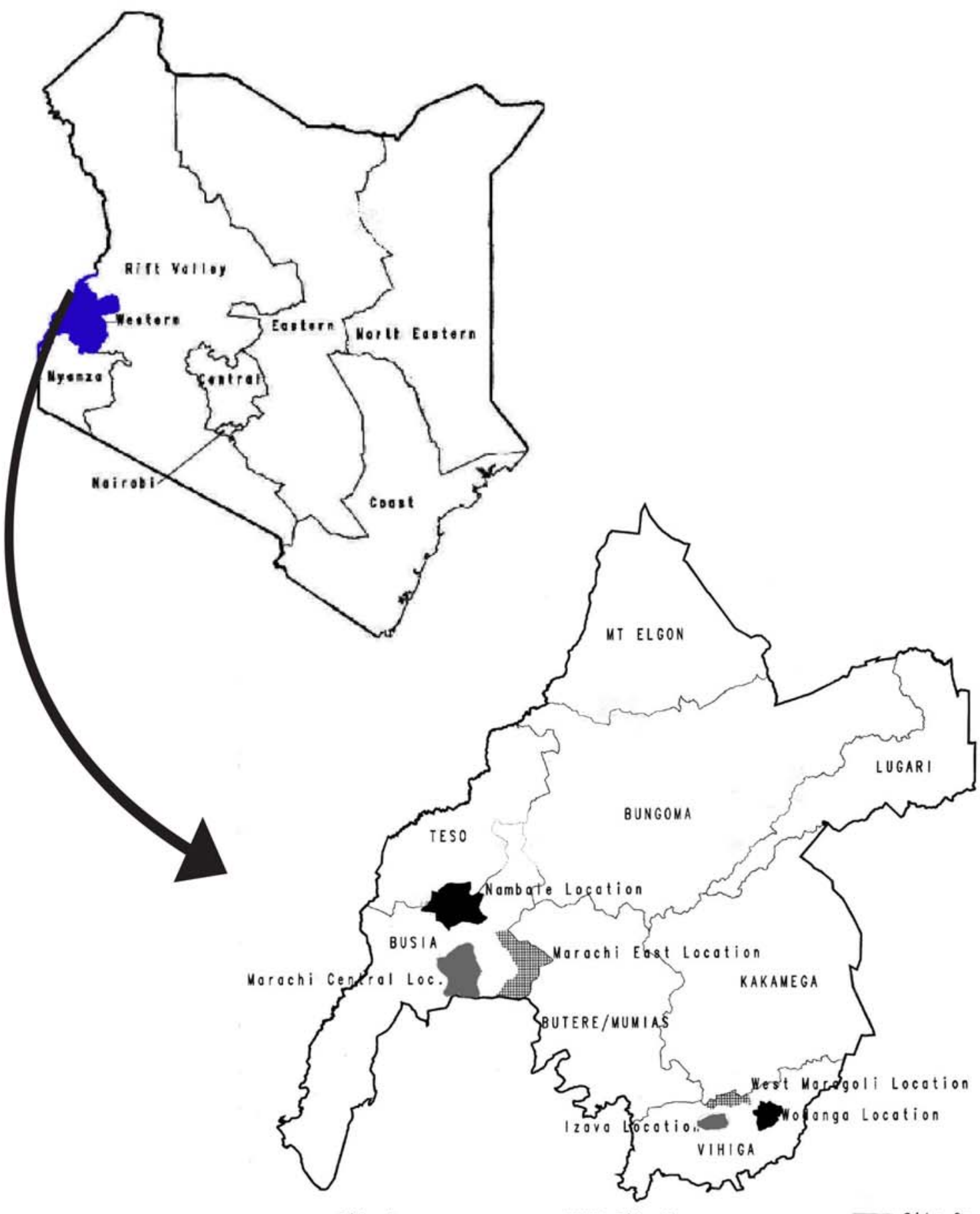

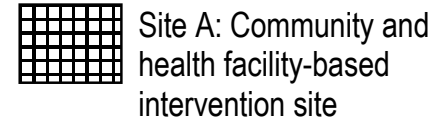

intervention site
Site B: Community

school and health facility

based intervention site
Site C: Control site 


\section{Data Collection}

\section{Population-based surveys}

The study sought to evaluate the interventions' impact separately on girls and boys, on younger and older adolescents, and on parents of both sexes. Consequently, the sample sizes needed to determine with statistical significance whether these interventions have had an impact or not were calculated separately for each of these six sub-groups using assumptions that are fully described in Appendix B (as is the sampling strategy to identify respondents). For the younger adolescents, it was the age of first sex; for the older adolescents it was use of contraception among the sexually active, and for the parents it was supporting the idea that adolescents should receive family planning information and services.

Under these assumptions, total sample sizes of 420 boys and 1554 girls aged 15-19 years, 570 boys and 1653 girls aged 10-14 years, and 381 male and 897 female parents were needed in each baseline and endline survey ${ }^{8}$. For each of the three pairs of intervention sites, this gave a sample size of 140 boys and 518 girls aged 15-19 years, 190 boys and 551 girls aged 10-14 years, and 127 male and 299 female parents. Table 1 describes the actual sample sizes achieved by age and sex of respondents by site and by survey. Response rates varying between $78-99$ percent were achieved, with the lowest rates among the older girls, probably because of the high levels of migration among this group to Nairobi in search of work (only those who lived in the household at the time of the survey were eligible for inclusion).

\section{Management information system}

A management information system (MIS) was established to collect information routinely on the number of activities undertaken by all three interventions, i.e. the intervention outputs. Record keeping forms were developed for all of the interventions' major activities, with forms specific for each activity and person responsible for recording the information. Every person responsible for recording information on the forms was trained in completing the forms correctly, and systems were put in place to facilitate collection of the forms so that the PATH office in Kakamega acted as a central collecting point. From here, the forms were sent to the PATH office in Nairobi where they were entered into an electronic database created specifically for this project.

Despite the tremendous effort put into developing this MIS, serious limitations were experienced with the quality of much of the data collected. Although problems had been envisaged for those working voluntarily on intervention activities, even among those fulltime, salaried workers (i.e. nurses, teachers, CDAs) who are used to completing similar forms as part of their routine work, the quality of the records kept were poor. As a consequence, analyses of the data that were collected have proven unreliable and invalid, and so it is not possible to present detailed measures of the project outputs. Only data collected through the MIS that are felt to be sufficiently valid to report are presented.

\section{Cost data}

The economic analysis of the interventions was designed with two objectives: to calculate the incremental costs of each intervention specific to the various phases of the project; and to provide information to Kenyan health, education, and social-welfare authorities on the costs to be considered when replicating the project in other areas of the country. sexual activity, and so larger samples are needed to detect a significant difference. 
Table 1: Respondent sample sizes by age, sex, site and survey

\begin{tabular}{|c|c|c|c|c|c|c|c|c|c|c|}
\hline \multirow[b]{2}{*}{ Adolescents } & \multicolumn{2}{|c|}{ Site A } & \multicolumn{2}{|c|}{ Site B } & \multicolumn{2}{|c|}{ Site C } & \multicolumn{2}{|c|}{ Total } & \multicolumn{2}{|c|}{ Response Rate (\%) } \\
\hline & Baseline & Endline & Baseline & Endline & Baseline & Endline & Baseline & Endline & Baseline & Endline \\
\hline Boys $10-14$ & 178 & 186 & 191 & 199 & 185 & 198 & 554 & 583 & 97 & 97 \\
\hline Boys $15-19$ & 129 & 169 & 146 & 143 & 122 & 143 & 397 & 455 & 95 & 99 \\
\hline Boys (NR) & 15 & 2 & 9 & 5 & 14 & 1 & 38 & 8 & - & - \\
\hline Total Boys & 322 & 357 & 346 & 347 & 321 & 342 & 989 & 1046 & 99 & 98 \\
\hline Girls $10-14$ yrs & 501 & 448 & 443 & 493 & 464 & 443 & 1408 & 1384 & 85 & 95 \\
\hline Girls $15-19$ yrs & 356 & 429 & 461 & 443 & 346 & 464 & 1163 & 1338 & 75 & 78 \\
\hline Girls (NR) & 50 & 4 & 16 & 1 & 27 & 3 & 93 & 6 & - & - \\
\hline Total Girls & 907 & 881 & 920 & 937 & 837 & 910 & 2664 & 2728 & 83 & 86 \\
\hline Total Adolescents & 1229 & 1238 & 1266 & 1284 & 1158 & 1252 & 3653 & 3774 & 87 & 89 \\
\hline \multicolumn{11}{|l|}{ Parents } \\
\hline Male & 99 & 119 & 104 & 112 & 143 & 117 & 346 & 348 & 91 & 92 \\
\hline Female & 237 & 264 & 277 & 264 & 331 & 267 & 845 & 795 & 94 & 94 \\
\hline Total Parents & 336 & 383 & 381 & 376 & 474 & 384 & 1192 & 1143 & 93 & 93 \\
\hline
\end{tabular}


The costs of three stages in developing and implementing the interventions (planning, introducing interventions, and implementation and monitoring) were estimated. Planning costs included those associated with development of the intervention, such as the IEC component, and the training programme. Introduction costs included mainly those associated with training trainers or training those that would work in schools, clinics and the community to carry out the interventions. Implementation and monitoring included the costs of new educational, clinic and community activities and the costs of supervising those activities. Evaluation costs were excluded, although formative research to design the intervention was included in the planning costs.

The inputs were identified and the quantity of each input used was measured, enabling a unit cost to be assigned to each input; the total cost was estimated by multiplying the quantity used by the unit cost. Customized spreadsheets were used to collect information on the various inputs (i.e., labour, materials and capital) used in each intervention. In addition, information was collected on the salaries and benefits and expected annual work hours of each person that worked on the project in order to estimate hourly compensation so that we could determine labour costs (hourly compensation multiplied by hours spent on a particular activity). For more information, see Appendix C. 


\section{STUDY FINDINGS}

This report presents findings that directly evaluate and cost the interventions. Unless otherwise indicated, weighted data are used throughout to ensure that the sample responses represent responses of the study population as controlled by Location, age, and sex. The datasets for adolescents were weighted by Location, age and sex, as described in Appendix B.

First, the socio-demographic characteristics of the adolescents and their parents living in the study sites are presented. This gives a description of the population being served by the interventions and ascertains whether there are any differences between the sites or the samples surveyed that may influence interpretation of the results.

Secondly, exposure to and participation in the intervention is presented. Interventions such as these cannot be expected to reach every single person in the study site, nor can it be assumed that every person had a similar experience with the intervention activities. Some data from the MIS describe the broad coverage achieved by each intervention in terms of the number and distribution of the key activities completed during the intervention period. Survey data are then used to measure the proportion of the population who were exposed to the interventions through hearing about it or directly participating in one or more of the activities.

Thirdly, the impact of these interventions on the knowledge, attitudes and behaviour of both adolescents and parents is evaluated by making comparisons between the baseline and endline surveys in the intervention sites, and also with the findings from the control sites. Only those differences that are statistically significant between the baseline and endline measures at the level of 0.05 or higher are considered meaningful, that is, indicative of a probable change. For all tables, a two-sample, two-tailed test of differences in proportions was used to judge positive and negative differences; levels of significance are indicated through using $*$ or $* * 9$. Finally, the costs of implementing these interventions are described.

\section{Socio-demographic characteristics of adolescents and parents}

Table 2 describes the population living in the study sites. For most socio-demographic characteristics there is no difference, either between the sites or between the baseline and endline surveys. This is interpreted to mean that any differences in measures of the key indicators that are found between the baseline and endline surveys are most probably due to the influence of the interventions themselves, rather than to the particular characteristics of the people living in the study sites. Where differences between sites or over time do occur for a characteristic, it is taken into account when interpreting the findings.

Catholicism and Pentecostalism were the predominant religions, comprising over two-thirds of adolescents and their parents, but religious affiliation varied by district, with those living in Busia more likely to be Catholic and those in Vihiga more likely to be Pentecostal ${ }^{10}$. Many schools in Nambale Location, Busia were set up by the Catholic Church, are still managed by a Church board and most of the teachers are Catholic, which may have an influence on the way the curriculum was implemented in those schools. However, discussions with the school heads suggested that this had little effect on the way in which the schools were run.

\footnotetext{
$9 \quad *=\quad$ significant at 0.05 level of significance

$* *=\quad$ significant at 0.01 level of significance
}

The proportion reporting to be Pentecostal probably increased in the endline survey due to differences in coding responses, as there were also large decreases in the proportions reporting 'other evangelical'. 
Table 2: Socio-demographic characteristics of all adolescents

\begin{tabular}{|c|c|c|c|c|c|c|}
\hline \multirow{2}{*}{ Characteristics } & \multicolumn{2}{|c|}{ Sites A } & \multicolumn{2}{|c|}{ Sites B } & \multicolumn{2}{|c|}{ Sites C } \\
\hline & $\begin{array}{c}\text { Baseline } \\
N=1229\end{array}$ & $\begin{array}{l}\text { Endline } \\
N=1238\end{array}$ & $\begin{array}{c}\text { Baseline } \\
N=1266\end{array}$ & $\begin{array}{l}\text { Endline } \\
N=1284\end{array}$ & $\begin{array}{c}\text { Baseline } \\
N=1158\end{array}$ & $\begin{array}{l}\text { Endline } \\
N=1252\end{array}$ \\
\hline $\begin{array}{l}\text { Religion } \\
\text { Catholic } \\
\text { Pentecostal } \\
\text { Other Evangelical } \\
\text { Friends/Quakers } \\
\text { Salvation Army } \\
\text { Anglican } \\
\text { None/Don't Know }\end{array}$ & $\begin{array}{c}56 \\
15 \\
9 \\
9 \\
7 \\
4 \\
1\end{array}$ & $\begin{array}{c}51 \\
23^{*} \\
1^{*} \\
11 \\
8 \\
3 \\
3\end{array}$ & $\begin{array}{l}38 \\
31 \\
12 \\
7 \\
6 \\
7 \\
0\end{array}$ & $\begin{array}{c}35 \\
38^{*} \\
2^{*} \\
8 \\
6 \\
8 \\
3\end{array}$ & $\begin{array}{c}35 \\
29 \\
10 \\
8 \\
3 \\
15 \\
0\end{array}$ & $\begin{array}{c}35 \\
35 \\
1^{*} \\
7 \\
3 \\
15 \\
5\end{array}$ \\
\hline $\begin{array}{l}\text { Ever attended school } \\
\text { Level of schooling completed } \\
\text { Primary school } \\
\text { Secondary school } \\
\text { Currently attends school }\end{array}$ & $\begin{array}{c}96 \\
N=1187 \\
86 \\
9 \\
81\end{array}$ & $\begin{array}{c}96 \\
\mathrm{~N}=1197 \\
87 \\
9 \\
82\end{array}$ & $\begin{array}{c}97 \\
\mathrm{~N}=1217 \\
86 \\
10 \\
85\end{array}$ & $\begin{array}{c}96 \\
\mathrm{~N}=1243 \\
83 \\
13 \\
87\end{array}$ & $\begin{array}{c}98 \\
N=1128 \\
88 \\
9 \\
84\end{array}$ & $\begin{array}{c}97 \\
\mathrm{~N}=1226 \\
86 \\
11 \\
81\end{array}$ \\
\hline $\begin{array}{l}\text { Literacy } \\
\text { Can read Kiswahili } \\
\text { Can read English }\end{array}$ & $\begin{array}{l}85 \\
65\end{array}$ & $\begin{array}{l}88 \\
71\end{array}$ & $\begin{array}{l}88 \\
75\end{array}$ & $\begin{array}{l}93 \\
85\end{array}$ & $\begin{array}{l}87 \\
70\end{array}$ & $\begin{array}{l}91 \\
76\end{array}$ \\
\hline $\begin{array}{l}\text { Marital Status } \\
\text { Single / Never married } \\
\text { Married }\end{array}$ & $\begin{array}{c}96 \\
3\end{array}$ & $\begin{array}{c}97 \\
2\end{array}$ & $\begin{array}{c}98 \\
2\end{array}$ & $\begin{array}{c}98 \\
2\end{array}$ & $\begin{array}{c}99 \\
1\end{array}$ & $\begin{array}{c}97 \\
3\end{array}$ \\
\hline $\begin{array}{l}\text { Living with: } \\
\text { Both parents } \\
\text { Mother only } \\
\text { Father only } \\
\text { Other arrangements }\end{array}$ & $\begin{array}{c}71 \\
18 \\
2 \\
9\end{array}$ & $\begin{array}{c}68 \\
17 \\
4 \\
11\end{array}$ & $\begin{array}{c}63 \\
23 \\
3 \\
11\end{array}$ & $\begin{array}{c}60 \\
25 \\
4 \\
11\end{array}$ & $\begin{array}{l}63 \\
25 \\
3 \\
9\end{array}$ & $\begin{array}{c}62^{*} \\
23 \\
2 \\
13\end{array}$ \\
\hline $\begin{array}{l}\text { Father's Occupation } \\
\text { Work on farm } \\
\text { Self employed } \\
\text { Employed by someone } \\
\text { Professional } \\
\text { Retired / doesn't work } \\
\text { Don't know/other }\end{array}$ & $\begin{array}{l}32 \\
19 \\
23 \\
10 \\
8 \\
8\end{array}$ & $\begin{array}{l}32 \\
13 \\
24 \\
12 \\
15 \\
4\end{array}$ & $\begin{array}{l}28 \\
15 \\
24 \\
11 \\
15 \\
7\end{array}$ & $\begin{array}{l}29 \\
13 \\
23 \\
15 \\
14 \\
7\end{array}$ & $\begin{array}{l}17 \\
19 \\
27 \\
11 \\
18 \\
8\end{array}$ & $\begin{array}{l}23 \\
20 \\
22 \\
15 \\
16 \\
5\end{array}$ \\
\hline $\begin{array}{l}\text { Mother's Occupation } \\
\text { Work on farm } \\
\text { Self employed } \\
\text { Employed by someone } \\
\text { Retired / doesn't work } \\
\text { Work in the house } \\
\text { Don't know/other }\end{array}$ & $\begin{array}{l}59 \\
17 \\
6 \\
7 \\
9 \\
2\end{array}$ & $\begin{array}{c}52 \\
11 \\
6 \\
18 \\
11 \\
2\end{array}$ & $\begin{array}{c}57 \\
15 \\
7 \\
10 \\
9 \\
1\end{array}$ & $\begin{array}{c}52 \\
17 \\
8 \\
11 \\
8 \\
4\end{array}$ & $\begin{array}{c}47 \\
17 \\
6 \\
22 \\
6 \\
2\end{array}$ & $\begin{array}{c}44 \\
12 \\
6 \\
21 \\
15 \\
1\end{array}$ \\
\hline $\begin{array}{l}\text { Involved in sports } \\
\text { Member of club/group } \\
\text { Type of Club } \\
\text { Sport } \\
\text { Singing/drama } \\
\text { Church } \\
\text { Work-related } \\
\text { Other }\end{array}$ & $\begin{array}{c}74 \\
40 \\
N=507 \\
73 \\
25 \\
16 \\
7 \\
2\end{array}$ & $\begin{array}{c}82^{*} \\
48^{*} \\
N=619 \\
42^{* *} \\
25 \\
39^{*} \\
3 \\
7 \\
\end{array}$ & $\begin{array}{c}73 \\
34 \\
N=405 \\
69 \\
35 \\
21 \\
5 \\
2 \\
\end{array}$ & $\begin{array}{c}69 \\
41 \\
N=522 \\
29^{* *} \\
20^{*} \\
20 \\
1 \\
6\end{array}$ & $\begin{array}{c}77 \\
38 \\
N=444 \\
61 \\
32 \\
24 \\
8 \\
3\end{array}$ & $\begin{array}{c}77 \\
48^{*} \\
\mathrm{~N}=583 \\
47^{*} \\
21 \\
24 \\
6 \\
4\end{array}$ \\
\hline
\end{tabular}


Church services play an important part in peoples' lives, with the vast majority of adolescents and their parents attending a service at least once a week. Religious leaders and church youth groups (whose meetings over quarter of adolescents attend) are therefore accessible avenues for disseminating basic reproductive health messages and influencing attitudes and norms.

The vast majority of adolescents interviewed had ever attended school and over 80 percent were still in school. Very few adolescents $(3 \%)$ had never attended school, thus supporting the importance of a school-based intervention for reaching adolescents in Kenya. In comparison, 90 percent of fathers and 72 percent of mothers had ever attended school, with 71 percent of these having attended primary school only. Literacy in Kiswahili and in English were both high, although as would be expected, levels were significantly higher in the older age group. Parents were generally less likely to read either language.

Only three percent of adolescents interviewed were married, although this rises to 7.5 percent among the 15-19 year old girls ${ }^{11}$. Data from the KDHS show that, nationally, 15.4 percent of girls aged 15-19 years are married ${ }^{12}$, suggesting either that age at marriage among the Luhya is slightly higher than the national average, and/or that these surveys under-sampled married girls under 19 years. The latter is the more feasible explanation, as only households with at least one child aged 10-19 years were considered eligible for inclusion. Consequently, all households without an adolescent in this age range were excluded. As would be expected, most of the married girls interviewed had left school ( $90 \%$ in baseline, $83 \%$ in endline).

Approximately two-thirds of the adolescents were living with both parents and about one quarter with their mother only; very few lived with the father only. Between 10 and 15 percent have other living arrangements, including living with relatives or guardians, staying at boarding school, living with a spouse or living on their own.

Table 2 also describes the type of work that adolescents reported their parents do - however, a little under half $(45 \%)$ of the parents interviewed reported that they work as rural labourers or farm workers, and one quarter of all mothers interviewed said that they are homemakers with no other work outside.

The majority of adolescents reported belonging to youth groups or clubs and an even larger proportion participated in sports activities. Most adolescents who belonged to youth groups or clubs were also members of sports clubs, and so these could offer alternative ways of reaching many adolescents. Adolescents involved in a youth group or club were also more likely to attend school. One half of the out-of-school boys are not club members, and 12 percent of girls attend neither school nor a youth group. Consequently, alternative ways need to be found to reach the relatively small proportions of adolescents (3\% of all boys and $7 \%$ of all girls) that do not attend schools or clubs.

11 Due to data collection problems, the marital status of 707 adolescents ( $19 \%$ of the total) was not recorded during the baseline survey. The proportions in Table 2 describe those for whom their status is known.

12 Population Council. Facts about Adolescents from the Demographic and Health Survey - Statistical Tables for Program Planning: Kenya 1998, Population Council, New York: Population Council, 2001. 


\section{Exposure to and participation in the interventions}

Whether the interventions are able to influence the adolescents and parents is largely determined by the extent to which they were exposed to and participated in the activities. It is important to determine the levels of exposure for two reasons: to determine the feasibility of the intervention, as implemented through this pilot project, to reach those for whom it was intended; and to assess whether the degree of exposure to the interventions influences knowledge, attitudes or behaviour. To get an indication of the intensity with which the interventions were implemented, data collected through the KARHP MIS are presented (because of the data collection problems described elsewhere, only those data that are thought to be valid are presented).

\section{Activities completed}

\section{Community-based activities}

The three CDAs and religious leaders conducted a total of 60 meetings in the four locations, with each meeting attracting approximately 120 people (i.e. in the region of 7,200 people in total). Although it is not possible to disaggregate this by individual location, more meetings were held in the two locations in Vihiga district (West Maragoli in site A and Wodanga in site B) because only one CDA (in Wodanga) was active in site B.

The activities undertaken by the peer group leaders are described in Table $3 \mathrm{a}^{13}$. Again, because there was only one CDA active in site B, there were approximately twice as many peer educator groups created in site A (77) than in site B (43), and so the level of activities reported for site $\mathrm{A}$ is approximately double that for site $\mathrm{B}$. On average, the 77 peer groups in site A reported 4.98 activities per group, whereas the 43 groups in site B reported 3.86 activities per group. Given that the reporting period is 12 months, this represents less than one group activity every two months.

Table 3a: Total number of activities reported by community peer group leaders over 12 months by location and site

\begin{tabular}{|l|c|c|c|c|c|c|}
\hline \multicolumn{1}{|c|}{ Peer group activities } & \multicolumn{3}{|c|}{ Sites A } & \multicolumn{3}{c|}{ Sites B } \\
\hline & Total & $\begin{array}{c}\text { Marachi } \\
\text { East }\end{array}$ & $\begin{array}{c}\text { West } \\
\text { Maragoli }\end{array}$ & Total & Nambale & Wodanga \\
\hline Group discussions & 109 & 86 & 23 & 52 & 13 & 39 \\
\hline Drama presentations & 66 & 43 & 23 & 26 & 3 & 23 \\
\hline Outreach meetings & 32 & 22 & 10 & 22 & 3 & 19 \\
\hline Condom demonstrations & 78 & 63 & 15 & 12 & 3 & 9 \\
\hline Individual meetings & 42 & 37 & 5 & 24 & 5 & 19 \\
\hline Video shows & 13 & 3 & 10 & 22 & 5 & 17 \\
\hline IEC materials distribution & 18 & 11 & 7 & 0 & 0 & 0 \\
\hline Other & 26 & 11 & 15 & 8 & 0 & 8 \\
\hline Total & $\mathbf{3 8 4}$ & $\mathbf{2 7 6}$ & $\mathbf{1 0 8}$ & $\mathbf{1 6 6}$ & $\mathbf{3 2}$ & $\mathbf{1 3 4}$ \\
\hline
\end{tabular}


The 203 community peer educators reported a total of 15,669 individual meetings with adolescents over the same period, giving an average of 6.4 contacts per month per peer educator. The most frequent topic covered during these contacts was STIs (23\% of meetings), followed by relationships (13\%), drug use (12\%), teen pregnancy $(9 \%)$ and contraceptives $(9 \%)$. The level of activity for the individual peer educators is fairly evenly spread across the two sites.

\section{Health facility-based activities}

Services provided to adolescents in the health facilities were supposed to be recorded by the nurses on forms specifically developed for this purpose, with the intention that services could be reported by age and sex. Unfortunately, these data were poorly recorded and so it is not possible to report on the level of services provided to adolescents, or on trends over time. It would appear from the data that were recorded, however, that the services most frequently used by adolescents were for antenatal care and STIs.

Some of the community-based peer educators also held weekly or monthly meetings at the youth-friendly rooms in the four public health clinics. They would normally organize themselves into pairs or fours, with one or two peer educators of each sex. Again, no reliable data exist to describe the numbers of adolescents reached through these clinic-based meetings.

Initially, health providers from 12 private clinics were trained together with the staff from the four public clinics, although they did not create 'youth-friendly' areas because their premises were too small. Over time, their level of participation dwindled, and several of them went out of business, until by the end of the implementation phase none of them could be described as participating in the project. Moreover, as they did not submit any reports, it is impossible to know the level to which they were already providing services to adolescents, or whether their participation in the KARHP training led to any change.

\section{School-based activities}

Activities in the schools were organized either by the Guidance and Counselling teachers or by the peer educators. As can be seen in Table 3b, the peer educators preferred to hold group discussions, drama presentations and outreach meetings, but conducted very few other activities over the course of the 12 months. The teachers averaged 14 out of the 34 sessions of the Family Life Skills curriculum, although this represents a range from four schools that did not use the curriculum at all, to three schools that covered more than 35 sessions. The most frequently covered sessions were on relationships, assertiveness skills, STIs, teen pregnancy, drug abuse, sexual violence and communication skills. Contraception and abortion were covered infrequently. The teachers also held, on average, about two group discussions per month, which included meetings within the 'KARHP' clubs and discussions that arose after covering a specific unit of the curriculum. 
Table 3b: Mean number of activities reported per school over 12 months by activity and location

\begin{tabular}{|c|c|c|c|}
\hline School-based activities & $\begin{array}{l}\text { Site B total } \\
\text { (27 schools) }\end{array}$ & $\begin{array}{c}\text { Nambale } \\
\text { (12 schools) }\end{array}$ & $\begin{array}{c}\text { Wodanga } \\
\text { (15 schools) }\end{array}$ \\
\hline \multicolumn{4}{|c|}{ By Peer Educators } \\
\hline Group discussions & 26 & 12 & 37 \\
\hline Drama presentations & 16 & 9 & 21 \\
\hline Outreach meetings & 14 & 2 & 24 \\
\hline Condom demonstrations & 2 & 1 & 3 \\
\hline Individual meetings & 1 & 1 & 1 \\
\hline Video shows & 4 & 1 & 6 \\
\hline Other & 2 & 3 & 2 \\
\hline Total & 65 & 29 & 94 \\
\hline \multicolumn{4}{|c|}{ By Guidance and Counselling Teachers } \\
\hline Family Life Curriculum Session & 14 & 15 & 13 \\
\hline Group discussions & 25 & 37 & 15 \\
\hline Outreach meetings & 6 & 3 & 8 \\
\hline Condom demonstrations & 1 & 1 & 1 \\
\hline Video Shows & 2 & 2 & 2 \\
\hline Other & 7 & 10 & 4 \\
\hline Total & 55 & 68 & 43 \\
\hline
\end{tabular}

\section{Exposure to the interventions}

Determining the proportions of adolescents and parents that had been exposed to the interventions was measured during the endline survey by asking whether the respondent had ever heard of KARHP. As can be seen on Table 4, almost half of all those surveyed in the experimental sites had heard of KARHP, with those living in site B more likely to have heard of KARHP than those living in site A, and especially among adolescents. This reflects the fact that site B had the school-based intervention, reinforcing the important role that schools can play in Kenya as channels for reaching adolescents.

One-fifth of those living in the control sites reported hearing of KARHP, which probably reflects the high levels of mobility and interaction found in this part of Kenya, as well as the high profile of the project throughout the two districts. Given this potential contamination, many of the analyses that follow consider first those living within the geographic area of the intervention sites, and also those reporting exposure to the interventions only. 
Table 4: $\quad$ Proportion of all respondents reporting ever heard of KARHP

\begin{tabular}{|l|c|c|c|}
\hline & Sites A & Sites B & Sites C \\
\hline Adolescents & & & \\
Boys 10-14 yrs & 31 & $53^{* *}$ & 18 \\
Boys 15-19 yrs & 51 & $71^{* *}$ & 21 \\
Total Boys & $\mathbf{4 2}$ & $\mathbf{5 9}^{* *}$ & $\mathbf{1 9}$ \\
Girls 10-14 yrs & 34 & $67^{* *}$ & 15 \\
Girls 15-19 yrs & 55 & $72^{* *}$ & 25 \\
Total Girls & $\mathbf{4 3}$ & $\mathbf{6 9}^{* *}$ & $\mathbf{1 9}$ \\
Total Adolescents & $\mathbf{4 2}$ & $\mathbf{6 4}^{* *}$ & $\mathbf{1 9}$ \\
\hline Parents & & & \\
Male & 40 & $43^{*}$ & 18 \\
Female & 46 & $\mathbf{4 8}$ & 20 \\
Total Parents & $\mathbf{4 4}$ & $\mathbf{4 7}$ & $\mathbf{1 9}$ \\
\hline
\end{tabular}

Significance test is between Sites A and B only

As can be seen in Table 5, the proportions of adolescents and parents who reported having ever participated in a KARHP activity were also high. The adolescents living in Site B, the site with the school-based intervention, were more likely to have participated in an activity, whereas the adults were more likely to have participated in a KARHP activity if they lived in Site A, probably because there were two active CDAs compared with one in site B. The low levels of participation by respondents in Site $\mathrm{C}$ indicate that there may have been some contamination, probably through visiting relatives or friends in one of the experimental sites, as none of the activities themselves were carried out in the control sites.

Table 5: Proportion of all respondents reporting ever participated in a KARHP activity

\begin{tabular}{|l|c|c|c|}
\hline & Sites A & Sites B & Sites C \\
\hline Adolescents & & & \\
Boys 10-14 yrs & 15 & $30^{* *}$ & 5 \\
Boys 15-19 yrs & 28 & $38^{*}$ & 10 \\
Total Boys & $\mathbf{2 1}$ & $\mathbf{3 3}^{*}$ & $\mathbf{7}$ \\
Girls 10-14 yrs & 15 & $34^{* *}$ & 2 \\
Girls 15-19 yrs & 27 & $37^{*}$ & 5 \\
Total Girls & $\mathbf{1 9}$ & $\mathbf{3 5}^{\star *}$ & $\mathbf{3}$ \\
Total Adolescents & $\mathbf{2 0}$ & $\mathbf{3 5}^{\star *}$ & $\mathbf{3}$ \\
\hline Parents & & & \\
Male & $21^{*}$ & 15 & 4 \\
Female & $23^{*}$ & 17 & 6 \\
Total Parents & $\mathbf{2 2}^{*}$ & $\mathbf{1 7}$ & $\mathbf{6}$ \\
\hline
\end{tabular}

Significance test is between Sites A and B only 
When asked to specify the activity in which they had participated, two-thirds of the adolescents overall indicated that it had been a school-based activity, whereas 80 percent of the parents described a community-based activity (see Table 6). Participation in facility-based interventions was minimal ( $5 \%$ adolescent, $14 \%$ parents). The totals come to more than 100 percent because some respondents participated in more than one type of activity. Frequency of participation was not determined. As can be seen in Table 6, almost one-third of adolescents reported participating in school-based interventions in Site A. This may reflect the possibility that their home is in a location in sites A or C but they go to school in a site B location (the surveys were undertaken during school holidays), or that they mistook similar activities in their schools for the KARHP activities (although the question specifically referred to 'KARHP' by name).

Table 6: Proportion of respondents reporting participation in a KARHP activity by type of activity

\begin{tabular}{|l|c|c|}
\hline & Sites A & Sites B \\
\hline Boys & $\mathrm{n}=69$ & $\mathrm{n}=116$ \\
Community-based & $70^{* *}$ & 22 \\
Health-based & 7 & 5 \\
School-based & 27 & $90^{* *}$ \\
Girls & $\mathrm{n}=158$ & $\mathrm{n}=334$ \\
Community-based & $62^{\star *}$ & 16 \\
Health-based & 12 & 2 \\
School-based & 33 & $90^{* *}$ \\
Adolescents & $\mathrm{n}=227$ & $\mathrm{n}=450$ \\
Community-based & $66^{* *}$ & 19 \\
Health-based & 9 & 3 \\
School-based & 30 & $90^{* *}$ \\
\hline Parents & & \\
Male & $\mathrm{n}=39$ & $\mathrm{n}=29$ \\
Community-based & $94^{*}$ & 73 \\
Health-based & 10 & 17 \\
School-based & 3 & $48^{*}$ \\
Female & $\mathrm{n}=88$ & $\mathrm{n}=65$ \\
Community-based & $93^{*}$ & 69 \\
Health-based & 11 & 14 \\
School-based & 2 & $48^{*}$ \\
Total Parents & $\mathrm{n}=127$ & $\mathrm{n}=94$ \\
Community-based & $93^{*}$ & 70 \\
Health-based & 11 & 15 \\
School-based & 2 & $48^{*}$ \\
\hline
\end{tabular}

Peer educators were an integral component of all three interventions and approximately one quarter of all adolescents in the two intervention sites reported receiving information from a peer educator (Table 7). Contact with peer educators was significantly higher in Site B, 
presumably because of the additional presence of the school-based peer educators. Contact was also higher among the older adolescents and slightly higher among boys than girls.

Table 7: Proportion of all adolescents reporting ever received information from a peer educator

\begin{tabular}{|l|c|c|c|}
\hline & Sites A & Sites B & Sites C \\
\hline Adolescents & & & \\
Boys 10 - 14 yrs & 17 & $21^{*}$ & 4 \\
Boys 15-19 yrs & 32 & $40^{*}$ & 13 \\
Total Boys & $\mathbf{2 3}$ & $\mathbf{2 9}^{*}$ & $\mathbf{8}$ \\
Girls 10 - 14 yrs & 13 & $23^{*}$ & 3 \\
Girls 15-19 yrs & 31 & 26 & 7 \\
Total Girls & $\mathbf{2 0}$ & $\mathbf{2 5}^{*}$ & $\mathbf{5}$ \\
Total Adolescents & $\mathbf{2 2}$ & $\mathbf{2 7}^{*}$ & $\mathbf{6}$ \\
\hline
\end{tabular}

Comparison is between Sites A and B only

\section{Effect on knowledge about sexual and reproductive health}

\section{Sources of information}

One of the assumptions underlying this study was that adolescents generally receive insufficient, inaccurate and possibly judgemental information about sexuality and reproductive health, and so emphasis was placed on developing interventions that would improve access to and the quality of information available. Table 8 describes adolescents' awareness of selected sexual and reproductive health functions before and after the interventions were introduced.

As would be expected, levels of awareness of these functions was already higher among the older age groups, and were fairly similar among girls and boys. Some significant improvements in awareness of virtually all functions can be seen after the interventions among the younger adolescents and older girls living in site A, and in site B for the younger girls (and for boys concerning dating). This suggests that the community-based activities are increasing awareness of these issues, and that the school-based intervention does not add to this. 
Table 8: Proportion of adolescents who have ever heard of sexual and reproduction functions

\begin{tabular}{|l|c|c|c|c|c|c|}
\hline & \multicolumn{2}{|c|}{ Site } & \multicolumn{2}{c|}{ Site B } & \multicolumn{2}{c|}{ Site C } \\
\hline & Baseline & Endline & Baseline & Endline & Baseline & Endline \\
\hline Boys 10-14 & $\mathrm{N}=178$ & $\mathrm{~N}=186$ & $\mathrm{~N}=191$ & $\mathrm{~N}=201$ & $\mathrm{~N}=185$ & $\mathrm{~N}=199$ \\
\hline How body works & 43 & 44 & 40 & 43 & 34 & 37 \\
\hline Menstruation & 36 & $51^{*}$ & 38 & 40 & 38 & 38 \\
\hline Ejaculation & 18 & $43^{*}$ & 33 & 38 & 25 & 39 \\
\hline Dating & 31 & $47^{*}$ & 44 & $56^{*}$ & 45 & 53 \\
\hline Sexual intercourse & 58 & $79^{* *}$ & 68 & 71 & 63 & 64 \\
\hline How girls get pregnant & 38 & $49^{*}$ & 43 & 58 & 49 & 42 \\
\hline Boys 15-19 & $\mathrm{N}=129$ & $\mathrm{~N}=171$ & $\mathrm{~N}=146$ & $\mathrm{~N}=146$ & $\mathrm{~N}=122$ & $\mathrm{~N}=143$ \\
\hline How body works & 75 & 76 & 78 & 71 & 70 & 66 \\
\hline Menstruation & 84 & 84 & 88 & 86 & 78 & 75 \\
\hline Ejaculation & 78 & 83 & 84 & 83 & 76 & 72 \\
\hline Dating & 69 & 76 & 74 & $84^{*}$ & 72 & 84 \\
\hline Sexual intercourse & 92 & 98 & 91 & 95 & 88 & 87 \\
\hline How girls get pregnant & 78 & 79 & 86 & 83 & 77 & 70 \\
\hline Girls 10-14 yrs & $\mathrm{N}=498$ & $\mathrm{~N}=447$ & $\mathrm{~N}=441$ & $\mathrm{~N}=493$ & $\mathrm{~N}=463$ & $\mathrm{~N}=443$ \\
\hline How body works & 35 & $49^{*}$ & 44 & 49 & 28 & 32 \\
\hline Menstruation & 45 & $68^{* *}$ & 55 & $68^{*}$ & 47 & 53 \\
\hline Ejaculation & 11 & $36^{* *}$ & 21 & 28 & 13 & 18 \\
\hline Dating & 23 & $41^{*}$ & 41 & $52^{*}$ & 41 & 46 \\
\hline Sexual intercourse & 49 & $78^{* *}$ & 60 & $73^{*}$ & 49 & $59^{*}$ \\
\hline How girls get pregnant & 35 & $58^{* *}$ & 48 & $67^{* *}$ & 41 & 37 \\
\hline Girls 15-19 yrs & $\mathrm{N}=355$ & $\mathrm{~N}=431$ & $\mathrm{~N}=460$ & $\mathrm{~N}=443$ & $\mathrm{~N}=345$ & $\mathrm{~N}=464$ \\
\hline How body works & 64 & $79^{*}$ & 78 & 72 & 70 & 67 \\
\hline Menstruation & 92 & 97 & 96 & 96 & 93 & 92 \\
\hline Ejaculation & 54 & $76^{* *}$ & 69 & 67 & 49 & $62^{*}$ \\
\hline Dating & 68 & 76 & 77 & 80 & 52 & $82^{*}$ \\
\hline Sexual intercourse & $968^{*}$ & 94 & 92 & 87 & 88 \\
\hline How girls get pregnant & 81 & 87 & 89 & 85 & 78 \\
\hline
\end{tabular}

Comparisons are between baseline and endline within each site

To assess the role of the interventions as sources of information, adolescents were asked during the endline survey whether they had received any information on reproductive health issues during the past year, and if so, from which sources. Table 9 shows clearly that adolescents living in the two intervention sites are significantly more likely to have received any reproductive health information than adolescents living in the control site. 
Table 9: Proportion of all adolescents receiving any reproductive health information in the past year

\begin{tabular}{|l|c|c|c|}
\hline & Sites A & Sites B & Sites C \\
\hline Boys 10-14 yrs & $52^{* *}$ & $47^{*}$ & 27 \\
Boys 15-19 yrs & $68^{*}$ & $74^{* *}$ & 56 \\
Girls 10-14 yrs & $58^{* *}$ & $53^{* *}$ & 28 \\
Girls 15-19 yrs & $75^{* *}$ & $67^{*}$ & 50 \\
\hline
\end{tabular}

Significance tests are between site $C$ and sites $A$ and $B$

In all sites and for all adolescents, teachers were the most frequently cited source of reproductive health information. Teachers were more frequently cited in site B than in the other sites (but only significantly for older girls), highlighting the role played by the schoolbased intervention in these areas. Peer educators were also cited relatively frequently in sites A and B, particularly among the younger adolescents in Site B (23\% of girls; $31 \%$ of boys) indicating that the school-based educators were particularly useful for reaching the 10-14 year olds. Conversely, in site A it was the older adolescents who were more likely to report receiving information from a peer educator (18\% of girls; $21 \%$ of boys).

One intention of this study was to increase the degree of child-parent communication on sexuality and reproductive health issues, as parents can be an important and influential source, perhaps less so in terms of factual information but certainly with regard to attitudes and norms surrounding sexuality and reproductive health. Table 10 shows that girls, and especially older girls, are much more likely than boys to discuss such issues with their parents. Moreover, there were significant increases in child-parent communication reported after the intervention in Site A, among all girls and the older boys, but no changes in Sites B or C.

Table 10: Proportion of all adolescents discussing reproductive health issues with either parent during the previous six months

\begin{tabular}{|l|c|c|c|c|c|c|}
\hline \multirow{2}{*}{ Respondents } & \multicolumn{2}{|c|}{ Sites A } & \multicolumn{2}{c|}{ Sites B } & \multicolumn{2}{c|}{ Sites C } \\
\cline { 2 - 7 } & Baseline & Endline & Baseline & Endline & Baseline & Endline \\
\hline Boys 10-14 yrs & 24 & 24 & 24 & 15 & 22 & 30 \\
Boys 15-19 yrs & 19 & $33^{*}$ & 32 & 26 & 24 & 20 \\
Total Boys & $\mathbf{2 2}$ & $\mathbf{2 7}$ & $\mathbf{2 6}$ & $\mathbf{2 0}$ & 23 & 26 \\
Girls 10-14 yrs & 28 & $37^{*}$ & 23 & 30 & 26 & 28 \\
Girls 15-19 yrs & 40 & $52^{*}$ & 37 & 36 & 44 & 43 \\
Total Girls & $\mathbf{3 2}$ & $\mathbf{4 3}^{*}$ & $\mathbf{3 0}$ & $\mathbf{3 1}$ & $\mathbf{3 3}$ & $\mathbf{3 5}$ \\
Total Adolescents & $\mathbf{2 8}$ & $\mathbf{3 5}^{*}$ & $\mathbf{2 8}$ & $\mathbf{2 6}$ & $\mathbf{2 7}$ & $\mathbf{3 0}$ \\
\hline
\end{tabular}

Comparisons are between baseline and endline within each site

As was shown above, parent participation in KARHP activities was significantly greater in Site A than in Site B, and particularly in the community-based activities, in which emphasis on the importance of communicating with children was placed, suggesting that these messages may be prompting parents to initiate discussions with their children. Another reason for this difference may be that the school-based activities in Site B have addressed many of the reproductive health issues that adolescents, and particularly boys, would have 
discussed with their parents. If adolescents are getting their information from the school, then perhaps they do not feel it is necessary to discuss these issues with their parents.

All three interventions were intended, directly or indirectly, to increase adolescents' knowledge relating specifically to: contraception; preventing sexually transmitted infections, including HV/AIDS; and timing of the fertile period.

\section{Contraception}

As Table 11 shows, the intervention in site A, but not in site B, has clearly improved adolescents' awareness of contraception. Increased awareness about contraception in Site A may well be due to the open discussions held with community development agents, parents and out of school peer educators, who were probably more willing to speak freely about contraceptives than school teachers and in-school peer educators. Indeed, adolescents who directly participated in community-based activities were significantly more likely to have ever heard of contraception than those who did not $(72 \%$ vs. $52 \%, \mathrm{p}<0.01)$.

The addition of the school-based activities in Site B does not appear to have contributed a marginal increase in knowledge at the population level. However, analysis of those adolescents directly exposed to the school-based intervention reveals that they had significantly higher levels of awareness of contraception than those who were not exposed $(65 \%$ vs. $52 \%, p<0.01)$. This may explain why, in site B, the teacher was cited as the first and most important source of information on contraception by over half of the adolescents, and these proportions had increased significantly after the intervention.

Table 11: Proportion of all adolescents reporting ever heard about contraception

\begin{tabular}{|l|c|c|c|c|c|c|}
\hline & \multicolumn{2}{|c|}{ Sites A } & \multicolumn{2}{c|}{ Sites B } & \multicolumn{2}{c|}{ Sites C } \\
\cline { 2 - 7 } & Baseline & Endline & Baseline & Endline & Baseline & Endline \\
\hline Boys 10 - 14 yrs & 34 & $47^{*}$ & 46 & 43 & 32 & 28 \\
Boys 15-19 yrs & 67 & 76 & 79 & 74 & 68 & 61 \\
Total Boys & $\mathbf{4 7}$ & $\mathbf{6 0}^{*}$ & $\mathbf{5 9}$ & $\mathbf{5 6}$ & $\mathbf{4 7}$ & $\mathbf{4 2}$ \\
Girls 10-14 yrs & 29 & $4^{*}$ & 42 & 42 & 25 & 28 \\
Girls 15-19 yrs & 70 & $86^{*}$ & 74 & 74 & 69 & 70 \\
Total Girls & $\mathbf{4 5}$ & $\mathbf{6 3}^{*}$ & $\mathbf{5 5}$ & $\mathbf{5 6}$ & $\mathbf{4 3}$ & $\mathbf{4 6}$ \\
Total Adolescents & $\mathbf{4 6}$ & $\mathbf{6 1}^{*}$ & $\mathbf{5 7}$ & $\mathbf{5 6}$ & $\mathbf{4 5}$ & $\mathbf{4 4}$ \\
\hline
\end{tabular}

Comparisons are between baseline and endline within each site

Those adolescents who indicated having heard about contraception were then asked which specific methods they knew. Table 12 indicates that awareness ${ }^{14}$ of condoms, pills and injectables increased dramatically and significantly for virtually all groups of adolescents, and in both intervention and control sites. Consequently, it would appear that the interventions had little impact over and above other awareness raising activities that appear to have been occurring in the districts at this time. The only possible exception was awareness of the injectable, which increased much more among the younger adolescents in the intervention sites than in the control sites. It should be noted that site A had lower baseline levels of awareness than other sites, but also showed greater increase over time.

14 Awareness of contraceptive methods was measured by including both spontaneous and prompted responses, in line with the measure used in the DHS. 
Table 12: Proportion of adolescents that are aware of contraception reporting ever heard of specific methods

\begin{tabular}{|l|c|c|c|c|c|c|}
\hline \multirow{2}{*}{} & \multicolumn{2}{|c|}{ Sites A } & \multicolumn{2}{c|}{ Sites B } & \multicolumn{2}{c|}{ Sites C } \\
\cline { 2 - 7 } & Baseline & Endline & Baseline & Endline & Baseline & Endline \\
\hline Boys 10-14 yrs & $\mathrm{N}=164$ & $\mathrm{~N}=107$ & $\mathrm{~N}=181$ & $\mathrm{~N}=86$ & $\mathrm{~N}=182$ & $\mathrm{~N}=60$ \\
Condom & 55 & $89^{* *}$ & 69 & $94^{* *}$ & 72 & $98^{*}$ \\
Pill & 27 & $73^{* *}$ & 39 & $75^{* *}$ & 32 & $67^{* *}$ \\
Injection & 28 & $71^{* *}$ & 30 & $70^{* *}$ & 26 & $46^{* *}$ \\
Boys 15 -19yrs & $\mathrm{N}=120$ & $\mathrm{~N}=138$ & $\mathrm{~N}=145$ & $\mathrm{~N}=110$ & $\mathrm{~N}=119$ & $\mathrm{~N}=95$ \\
Condom & 88 & $97^{*}$ & 94 & 99 & 93 & 98 \\
Pill & 62 & $86^{* *}$ & 72 & $89^{*}$ & 59 & $90^{* *}$ \\
Injection & 59 & $85^{* *}$ & 70 & $88^{*}$ & 55 & 83 \\
\hline Girls 10 - 14 yrs & $\mathrm{N}=463$ & $\mathrm{~N}=258$ & $\mathrm{~N}=344$ & $\mathrm{~N}=210$ & $\mathrm{~N}=332$ & $\mathrm{~N}=128$ \\
Condom & 35 & $84^{* *}$ & 59 & $93^{* *}$ & 52 & $90^{* *}$ \\
Pill & 19 & $86^{* *}$ & 32 & $79^{* *}$ & 29 & $65^{* *}$ \\
Injection & 22 & $80^{* *}$ & 34 & $80^{* *}$ & 27 & $55^{* *}$ \\
Girls 15-19 yrs & $\mathrm{N}=345$ & $\mathrm{~N}=380$ & $\mathrm{~N}=410$ & $\mathrm{~N}=336$ & $\mathrm{~N}=318$ & $\mathrm{~N}=352$ \\
Condom & 82 & $91^{*}$ & 89 & $97^{*}$ & 88 & $96^{*}$ \\
Pill & 70 & $93^{* *}$ & 81 & $93^{*}$ & 68 & $91^{* *}$ \\
Injection & 72 & $93^{* *}$ & 78 & $91^{*}$ & 65 & $84^{* *}$ \\
\hline Total Adolescents & $\mathrm{N}=1092$ & $\mathrm{~N}=883$ & $\mathrm{~N}=1080$ & $\mathrm{~N}=742$ & $\mathrm{~N}=951$ & $\mathrm{~N}=635$ \\
Condom & 62 & $91^{* *}$ & 77 & $96^{*}$ & 75 & $96^{*}$ \\
Pill & 41 & $85^{* *}$ & 52 & $85^{* *}$ & 46 & $82^{* *}$ \\
Injection & 41 & $83^{* *}$ & 51 & $83^{* *}$ & 42 & $72^{* *}$ \\
\hline
\end{tabular}

Those who had ever heard of the condom were then asked to list, without prompting, the key steps in correctly using a condom ${ }^{15}$. Even after the interventions, adolescents' knowledge was universally low, and a lack of significant differences between the intervention and control sites indicates that knowledge of condom use was not strongly promoted in either sites A or B. Although boys tend to be better informed than girls, more than 40 percent of boys knowing about the condom could not name any steps in its use. Those adolescents exposed to the school-based interventions were significantly less likely than those not exposed to know any steps $(49 \%$ vs. $35 \%, \mathrm{p}<0.01)$.

\section{Preventing STIs including HIVIAIDS}

The interventions in sites A and B have clearly had an effect on adolescents' awareness of STIs, including HIV/AIDS. During the endline survey ${ }^{16}$, every age group of adolescent in the intervention sites was significantly more likely to be able to name at least one STI than those in the control sites (see Table 13), except older boys at sites B. Due to the substantial

\footnotetext{
15 Differences in the way the questions were asked prevent comparisons with the baseline survey.

16 Differences in the way the questions were asked prevent comparisons with the baseline survey.
} 
nationwide efforts aimed specifically at improving awareness of HIV/AIDS, almost universal awareness was found by the time of the endline survey (94-99\%).

Table 13: Proportions of adolescents in the endline survey reporting they have ever heard of at least one STI

\begin{tabular}{|l|c|c|c|}
\hline & Sites A & Sites B & Sites C \\
\hline Boys 10-14 & $76^{*}$ & $67^{*}$ & 52 \\
Boys 15-19 & $96^{*}$ & 91 & 83 \\
\hline Girls 10-14 & $77^{* *}$ & $69^{*}$ & 52 \\
Girls 15-19 & $94^{*}$ & $88^{*}$ & 78 \\
\hline
\end{tabular}

Significances are compared between sites $A$ and $B$ with site $C$

Those who were aware of STIs and/or HIV/AIDS were asked what a person could do to avoid getting an infection; the responses (spontaneously given) are presented on Table 14. Among the parents, the most increases occurred in site A, although increases in personal fidelity were also found in Site B. Conversely, there was a significant decrease among parents in site B citing partner fidelity.

Table 14: Proportion of respondents who have ever heard of STIs or HIVIAIDS knowing ways of avoiding infection

\begin{tabular}{|l|c|c|c|c|c|c|}
\hline \multirow{2}{*}{ RESPONDENTS } & \multicolumn{2}{|c|}{ Sites A } & \multicolumn{2}{c|}{ Sites B } & \multicolumn{2}{c|}{ Sites C } \\
\cline { 2 - 7 } & Baseline & Endline & Baseline & Endline & Baseline & Endline \\
\hline Total Boys & $\mathrm{N}=289$ & $\mathrm{~N}=357$ & $\mathrm{~N}=331$ & $\mathrm{~N}=347$ & $\mathrm{~N}=306$ & $\mathrm{~N}=342$ \\
Abstain & 31 & $53^{* *}$ & 43 & $54^{* *}$ & 38 & 43 \\
Use condom & 35 & $50^{*}$ & 35 & 39 & 32 & 43 \\
Be faithful personally & 14 & 25 & 15 & 13 & 14 & 13 \\
Ask partner to be faithful & 18 & 28 & 15 & 11 & 13 & 13 \\
\hline Total Girls & $\mathrm{N}=812$ & $\mathrm{~N}=876$ & $\mathrm{~N}=882$ & $\mathrm{~N}=937$ & $\mathrm{~N}=766$ & $\mathrm{~N}=910$ \\
Abstain & 37 & $64^{* *}$ & 46 & 56 & 40 & 38 \\
Use condom & 20 & $35^{*}$ & 23 & 27 & 18 & $36^{*}$ \\
Be faithful personally & 11 & 21 & 12 & 15 & 10 & 15 \\
Ask partner to be faithful & 17 & 23 & 17 & 11 & 10 & 19 \\
\hline Total Male Parents & $\mathrm{N}=99$ & $\mathrm{~N}=119$ & $\mathrm{~N}=104$ & $\mathrm{~N}=112$ & $\mathrm{~N}=143$ & $\mathrm{~N}=117$ \\
Abstain & 30 & $44^{*}$ & 39 & 44 & 45 & $57^{*}$ \\
Use condom & 35 & $55^{* *}$ & 43 & 48 & 38 & 45 \\
Be faithful personally & 24 & $54^{* *}$ & 34 & $42^{*}$ & 27 & 31 \\
Ask partner to be faithful & 41 & $52^{*}$ & 49 & $32^{*}$ & 30 & $47^{* *}$ \\
\hline Total Female Parents & $\mathrm{N}=237$ & $\mathrm{~N}=257$ & $\mathrm{~N}=277$ & $\mathrm{~N}=264$ & $\mathrm{~N}=331$ & $\mathrm{~N}=267$ \\
Abstain & 35 & $42^{*}$ & 43 & 50 & 43 & 44 \\
Use condom & 33 & 37 & 35 & 41 & 35 & $44^{*}$ \\
Be faithful personally & 29 & $52^{* *}$ & 22 & $44^{* *}$ & 21 & $31^{*}$ \\
Ask partner to be faithful & 40 & $55^{* *}$ & 40 & $29^{*}$ & 36 & 42 \\
\hline
\end{tabular}

Comparisons are between baseline and endline within each site 
Among the adolescents, there were significant increases in site A in the proportions knowing about abstinence and using condoms, and non-significant increases in awareness of being faithful. In site B, the only significant increase was among boys knowing about abstinence, although there were also non-significant increases for girls, and for both sexes, in knowing of condom use. It should be noted, however, that there were also large (and for girls, significant) increases in knowledge of condom use in the control site. This is probably due to the many condom promotion campaigns going on throughout Western Province.

Among those adolescents directly exposed to the school-based intervention, knowledge of abstinence was significantly higher among all adolescents ( $64 \%$ vs. $49 \%, \mathrm{p}<0.05)$ than among adolescents not exposed to the school-based intervention. Knowledge of the other preventive behaviours was similar across all groups, however, suggesting that teachers focused primarily on abstinence. Conversely, direct exposure to the community-based intervention significantly increased knowledge of all four preventive behaviours among boys, and three of the four behaviours among girls (the exception being faithfulness).

\section{Reproductive physiology}

One factor that could contribute to unwanted pregnancies, particularly amongst the majority of sexually active adolescents who do not use contraception or rely on natural methods (including withdrawal), is a lack of understanding of a woman's fertile period. Findings from the baseline survey indicated low levels of correct knowledge (8-9\% of boys; $14-19 \%$ of girls), with most adolescents stating that they didn't know. Despite the fact that the schoolbased curriculum included reproductive physiology, there was no change by the endline survey; indeed, the only significant change was a reduction in knowledge among girls in site B (from $19 \%$ to $9 \%, \mathrm{p}<0.05$ ).

\section{Attitudes towards adolescent sexuality and reproductive health}

Negative attitudes towards adolescents receiving information about sexual or reproductive issues is thought to constrain open discussions about these topics and to create barriers that may inhibit or prevent adolescents receiving accurate, unbiased and complete information. Moreover, for those who are sexually active, negative social norms and attitudes concerning sexual behaviour can inhibit access to services, thereby increasing their risk of unwanted pregnancies and infections, including HIV/AIDS. All three interventions, but especially the community-based interventions, were intended to facilitate open discussions around sexual and reproductive health, with the intention of encouraging less punitive attitudes.

\section{Premarital sex and childbearing}

The diagnostic study had indicated that conservative and gender-differentiated attitudes towards premarital sexuality predominated in the study sites. The baseline survey confirmed this - approval of men having pre-marital sex was between $13-22$ percent among boys, 5 11 percent among girls, and much lower among parents, i.e. between $0-5$ percent. The figures were lower still for approval of women having premarital sex.

In all sites and in all groups, these proportions were even smaller after the interventions, with significant decreases found among boys and girls in site A approving of men having premarital sex. Similarly high levels of disapproval were found for premarital childbearing, at both baseline and endline, with significant decreases in approval found among girls and boys in site A. Thus these interventions have not had any effect on liberalising attitudes towards premarital sex or childbearing; indeed, they appear to have reinforced the beliefs that sexual 
activity and childbearing should be within marriage only, thereby providing evidence that exposure to factual, accurate RH information does not promote more promiscuous attitudes.

Concerns were expressed in the diagnostic study that adolescents are becoming more likely to be sexually active before marriage than their parents were. The baseline survey found that the median age at first sex among those parents who reported having sex when they were 19 years or younger ${ }^{17}$ was 14 years for male parents $(n=224)$ and 15 years for female parents $(n=596)$, whereas the median age of marriage was 22 years for these males $(n=219)$ and 18 years for the females $(n=577)$. It would appear, therefore, that most parents were first having sex three to six years before they were married, and so premarital sex is not a modern phenomenon. Indeed, for those parents ever married or living with a partner, 88 percent of male and 66 percent of female parents had sex before they married. Clearly there is a considerable difference between publicly expressed attitudes and individual behaviour.

\section{Use of contraceptives and condoms}

The baseline survey revealed generally conservative attitudes towards the use of contraceptives (see Table 15). While this would be expected concerning their use by unmarried couples and adolescents, the widespread belief that married couples should not use contraception was somewhat surprising. The endline survey shows significant changes in these attitudes in sites A and C, suggesting a fairly appreciable change in attitude. In site B, however, these changes seem to have been resisted among adolescents, presumably because of the school-based intervention. Encouragingly, the proportions of adolescents approving condom use by sexually active adolescents increased significantly in both intervention sites and non-significant increases were also found in the control sites, suggesting that condom use by adolescents is generally becoming more acceptable and that the interventions may be reinforcing this.

Table 15: Proportions of those adolescents who have ever heard of contraception who approve use of contraceptives, including condoms

\begin{tabular}{|l|c|c|c|c|c|c|}
\hline \multirow{2}{*}{} & \multicolumn{2}{|c|}{ Sites A } & \multicolumn{2}{c|}{ Sites B } & \multicolumn{2}{c|}{ Sites C } \\
\cline { 2 - 7 } & Baseline & Endline & Baseline & Endline & Baseline & Endline \\
\hline Total Boys & $\mathrm{N}=223$ & $\mathrm{~N}=245$ & $\mathrm{~N}=257$ & $\mathrm{~N}=196$ & $\mathrm{~N}=244$ & $\mathrm{~N}=155$ \\
By married couples & 65 & $82^{*}$ & 64 & 64 & 53 & $74^{* *}$ \\
By unmarried couples & 50 & $66^{*}$ & 53 & 48 & 34 & $46^{*}$ \\
By unmarried adolescents & 51 & 58 & 47 & 50 & 43 & 40 \\
Condom use by sex. active adol. & 61 & $79^{*}$ & 63 & 71 & 57 & 64 \\
\hline Total Girls & $\mathrm{N}=573$ & $\mathrm{~N}=638$ & $\mathrm{~N}=666$ & $\mathrm{~N}=546$ & $\mathrm{~N}=555$ & $\mathrm{~N}=484$ \\
By married couples & 70 & $83^{*}$ & 62 & 68 & 54 & $62^{*}$ \\
By unmarried couples & 53 & 60 & 44 & 42 & 31 & 34 \\
By unmarried adolescents & 52 & 52 & 39 & 36 & 33 & 28 \\
Condom use by sex. active adol. & 59 & $72^{*}$ & 51 & $62^{*}$ & 48 & 54 \\
\hline
\end{tabular}

Comparisons are between baseline and endline within each site

17 Taking this sub-sample enables a comparison to be made with the equivalent sample of sexually experienced adolescents in this study, for whom the maximum age is 19 years. 
However, these population level findings obscure what is happening among those directly participating in the school-based intervention. Graph 1 shows that participation in the schoolbased activities has led to significantly large differences (significant at the $p<0.05$ level) in the proportions approving use of contraceptives by unmarried couples, and use of condoms by sexually active adolescents. This suggests that teachers may have instilled negative attitudes towards the use of contraception, including condoms, among those participating in the school-based activities.

\section{Graph 1: Proportions of adolescents knowing of contraception and approving use of contraceptives and condoms by exposure to the school-based intervention}

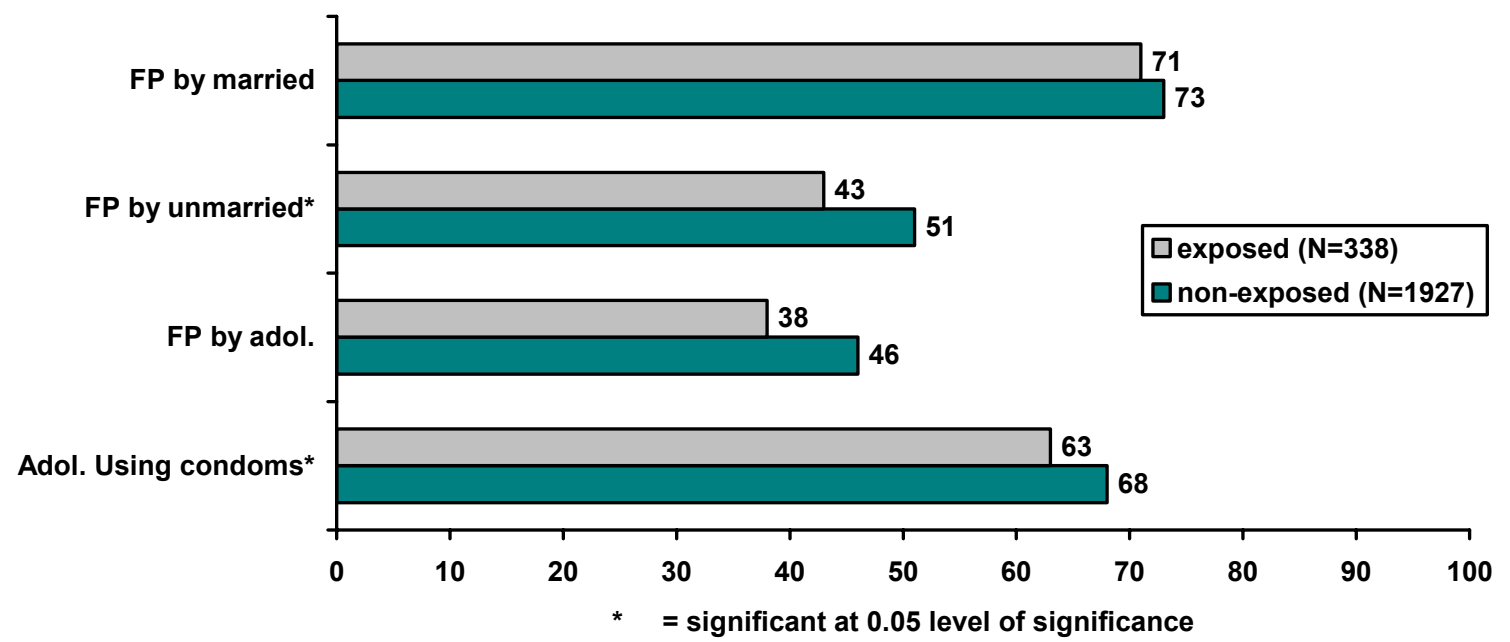

\section{Sexual behaviour}

The ultimate goal of these interventions was to influence sexual behaviour among adolescents, by encouraging and facilitating a delay in becoming sexually active, and for those already sexually active, enabling them to practise safer sex. Behaviour change is recognized as a long process and so it was not anticipated that significant changes would occur over the short duration of this intervention. Moreover, measuring sexual behaviour is notoriously difficult, and especially among adolescents. While every effort has been made to develop and use measures that give valid and reliable information, this methodological limitation should be noted when interpreting the findings.

It is also important to note that because marital status was incorrectly recorded for some respondents during the baseline survey, it is not possible to control for marital status when making comparisons over time. Consequently, the data presented are for all adolescents without disaggregation by marital status. Because married adolescents are more likely to be sexually active than non-married adolescents, the rates presented here for all adolescents are probably higher than those for unmarried adolescents. A comparison of those in the baseline whose marital status was known with those in the endline indicates no differences between the samples, and so comparisons between the two surveys for all adolescents are valid.

\section{Types and prevalence of sexual activity}

It is important to understand the types of sexual behaviours practised among adolescents before focusing specifically on sexual intercourse, as non-penetrative sex is recognised as an important form of 'safer sex' among those already sexually active. Adolescents were asked 
whether they had ever undertaken any of four types of sexual activity (see Table 16). While acknowledging the problems in eliciting this type of information, these results suggest that the majority of adolescents aged 10 to 19 years report having had little sexual activity of any kind. Even among the 15 - 19 year olds, over one-third of the boys and two-thirds of the girls reported having never undertaken any of these types of sexual activity.

Sample sizes for the younger age group were determined according to the expectation that a 40 percent decrease in the proportion ever having sexual intercourse would be achieved by the interventions (see Appendix B). Table 16 shows that this expectation was not achieved. However, in both intervention sites there was no change in levels of penetrative sex, whereas in the control site there were increases of more than 40 percent for both girls and boys ${ }^{18}$. Thus for the younger age group, there has been an effect of around the magnitude expected, although through a different mechanism.

Table 16: Proportions of all adolescents reporting sexual activity by type of activity

\begin{tabular}{|l|c|c|c|c|c|c|}
\hline & \multicolumn{2}{|c|}{ Sites A } & \multicolumn{2}{c|}{ Sites B } & \multicolumn{2}{c|}{ Sites C } \\
\cline { 2 - 7 } & Baseline & Endline & Baseline & Endline & Baseline & Endline \\
\hline Boys 10 - 14 yrs & $\mathrm{N}=166$ & $\mathrm{~N}=186$ & $\mathrm{~N}=186$ & $\mathrm{~N}=201$ & $\mathrm{~N}=171$ & $\mathrm{~N}=199$ \\
Mouth to mouth kissing & 4 & 4 & 5 & 4 & 5 & 5 \\
Touching private parts & 6 & 7 & 7 & 5 & 10 & 8 \\
Rubbing each other's private parts & 0 & 5 & 3 & 2 & 7 & 8 \\
Penetrative sex & 17 & 16 & 11 & 11 & 14 & 20 \\
None of the above & 73 & 84 & 86 & 79 & 76 & 72 \\
Boys 15 - 19 yrs & $\mathrm{N}=128$ & $\mathrm{~N}=171$ & $\mathrm{~N}=141$ & $\mathrm{~N}=146$ & $\mathrm{~N}=119$ & $\mathrm{~N}=143$ \\
Mouth to mouth kissing & 18 & 31 & 27 & 21 & 26 & 33 \\
Touching private parts & 20 & $33^{* *}$ & 26 & 24 & 33 & 35 \\
Rubbing each other's private parts & 14 & 22 & 22 & $9^{*}$ & 22 & 32 \\
Penetrative sex & 53 & $60^{*}$ & 50 & $41^{*}$ & 54 & 65 \\
None of the above & 44 & 37 & 45 & 51 & 41 & 31 \\
Girls 10 - 14 yrs & $\mathrm{N}=466$ & $\mathrm{~N}=446$ & $\mathrm{~N}=402$ & $\mathrm{~N}=493$ & $\mathrm{~N}=437$ & $\mathrm{~N}=442$ \\
Mouth to mouth kissing & 1 & 1 & 1 & 1 & 1 & 3 \\
Touching private parts & 1 & 1 & 2 & 0 & 1 & 3 \\
Rubbing each other's private parts & 0 & 1 & 1 & 0 & 1 & 3 \\
Penetrative sex & 3 & 3 & 3 & 3 & 3 & 8 \\
None of the above & 92 & 95 & 87 & 94 & 91 & 90 \\
Girls 15 - 19 yrs & $\mathrm{N}=352$ & $\mathrm{~N}=431$ & $\mathrm{~N}=449$ & $\mathrm{~N}=443$ & $\mathrm{~N}=339$ & $\mathrm{~N}=464$ \\
Mouth to mouth kissing & 15 & 32 & 17 & 20 & 16 & 23 \\
Touching private parts & 14 & 31 & 15 & 14 & 13 & $21^{*}$ \\
Rubbing each other's private parts & 7 & 23 & 11 & 6 & 9 & 18 \\
Penetrative sex & 32 & $42^{*}$ & 28 & 32 & 28 & $41^{*}$ \\
None of the above & 64 & 57 & 65 & 65 & 67 & 56 \\
\hline
\end{tabular}

Comparisons are between baseline and endline within each site

For the older age group, there have been significant increases in the proportions of girls and boys reporting penetrative sex group in site A, and for girls in the control site. Why this should have occurred over this relatively short time period is not clear. One factor could be 
that the mean age of respondents was significantly older in the endline survey for boys in site $\mathrm{A}$ and girls in site $\mathrm{C}$ (by $4-6$ months) but controlling for age does not change this finding.

A significant decrease occurred in the proportion of older boys reporting penetrative sex and rubbing each other's genitals, but no changes were found for older girls. Whether this is a genuine reduction or a change in reporting following exposure to the intervention is not clear. Moreover, when direct exposure to the school-based intervention is analysed ${ }^{19}$, an even stronger effect on reducing sexual activity is found among those participating in the KARHP activities. As can be seen in Graph 2, there are dramatic and highly significant differences in the reporting of all types of sexual activities between those exposed and not exposed to the school-based intervention. These differences were also found for both boys and girls; for example, among those exposed to the intervention, the proportion of boys ever having penetrative sex was $31 \%$ (vs. $44 \%$ among those not exposed) and for girls it was $14 \%$ (vs. $29 \%$ ).

\section{Graph 2: Proportions of all adolescents experiencing sexual activities by activity type and by exposure to the school-based intervention}

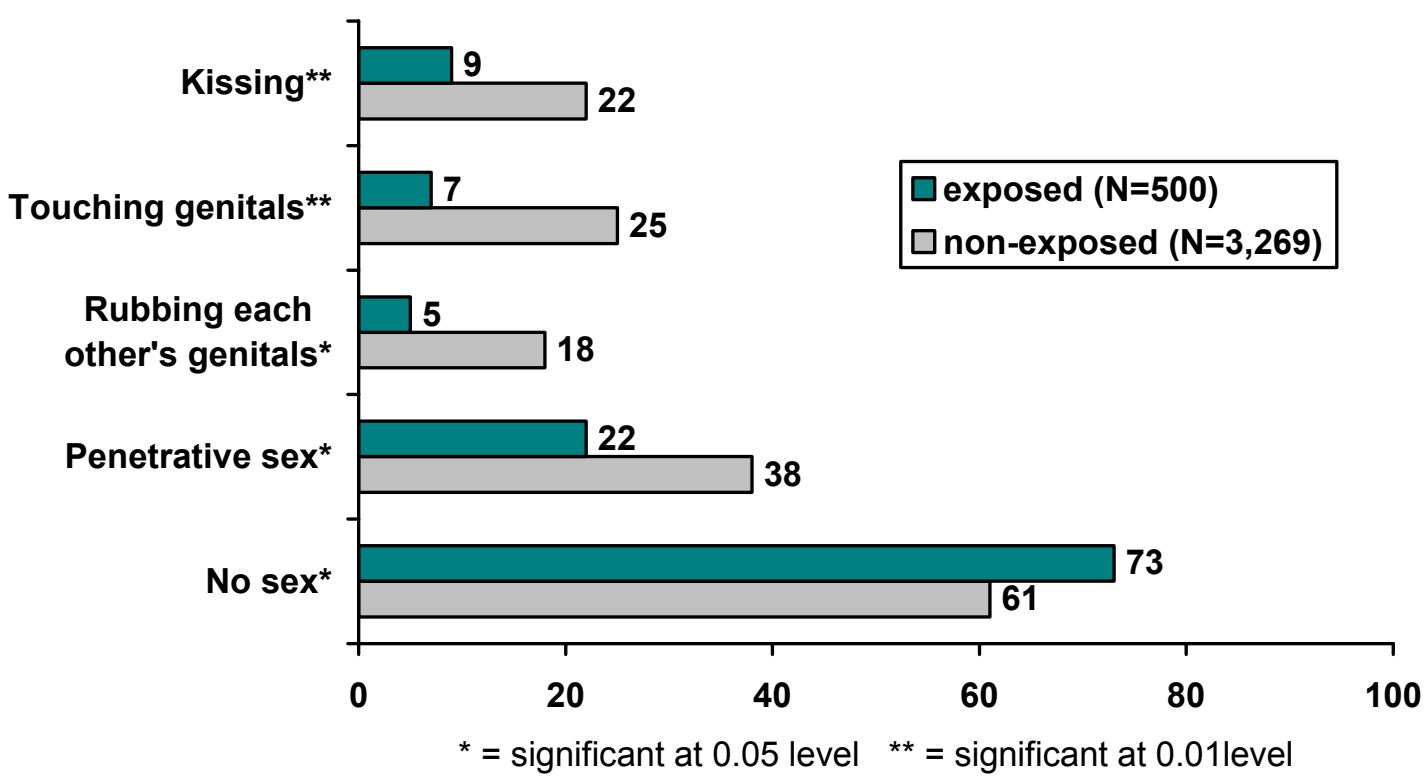

Penetrative sex is reported as the predominant type of sexual activity in which adolescents have engaged; for example, in all age groups penetrative sex is more common than kissing. This may reflect a misunderstanding when asked to describe their experiences of different types of sexual activity. But if true, it does suggest that the sexually experienced adolescents have a rather narrow experience of sexuality and may not be familiar with other nonpenetrative sexual activities that could be promoted as safer sex.

The possibility that there may be underreporting among respondents in sites A and B during the endline survey because of exposure to the intervention should be considered ${ }^{20}$. Those

As noted above, some adolescents interviewed in sites $\mathrm{A}$ and $\mathrm{C}$ reported exposure to the school-based intervention, possibly because they attend a school located in site B.

It is also important to consider that there was under-reporting during the baseline and more accurate reporting during the endline survey among the older adolescents who were interviewed in both rounds ( $36 \%$ of boys and $34 \%$ of girls). While there was virtually no difference among the boys, among the 
exposed to the school-based intervention have received messages that are highly critical of premarital sex, and so the respondents may well have felt uncomfortable about reporting any type of sexual activity in this context. Even allowing for this possibility, however, it would seem reasonable to conclude that the school-based intervention has probably had an effect on delaying adolescents' initiation of sexual behaviour.

\section{Timing of first sex}

A critical aspect of sexual behaviour is the timing of its initiation, and one of this project's ultimate goals was to facilitate a trend towards delaying sexual initiation. Analysis of data from the parents indicates that there has been a steady trend over the past decades towards earlier sexual initiation, with the median age among parents aged $25-40$ years (15-16 years) being younger than among parents over 40 years (17-18 years).

Among the adolescents who had been sexually active at the time of the interview, significant increases in the median age of initiation were found after the interventions in sites A and B for boys, and for girls in site B (see Table 17). Conversely, there were no significant changes in the control site. This suggests that the interventions may well be having an inhibiting effect by delaying sexual debut.

Table 17: Median age at first penetrative sex among all sexually active adolescents

\begin{tabular}{|l|c|c|c|c|c|c|}
\hline \multirow{2}{*}{} & \multicolumn{2}{|c|}{ Sites A } & \multicolumn{2}{c|}{ Sites B } & \multicolumn{2}{c|}{ Sites C } \\
\cline { 2 - 7 } & Baseline & Endline & Baseline & Endline & Baseline & Endline \\
\hline Boys & 13.9 & $14.3^{*}$ & 13.9 & $14.4^{*}$ & 13.9 & 14.1 \\
Girls & 15.1 & 15.4 & 14.5 & $15.0^{*}$ & 14.6 & 14.3 \\
\hline
\end{tabular}

Comparison by one-way analysis of variance

Trend analyses were undertaken to measure the average rate of increase in the proportions of sexually active adolescents within each age group for the range 13 - 19 years (see Appendix D). Among boys, there was no difference between the sites at the baseline, nor were there any significant changes in the trends over time within each site. However, at the endline, the trend in site B was significantly lower than in site $\mathrm{A}$ and site $\mathrm{C}$, and there was no difference between $\mathrm{A}$ and $\mathrm{C}$. The same analysis for the girls revealed that at the baseline there were no differences in the trends between the three sites. Over time the trend in site $\mathrm{C}$ become significantly greater, indicating that during the study period girls in the control site were becoming sexually active at a younger age. At the endline, as with the boys, the trend in site $\mathrm{B}$ was significantly lower than in sites $\mathrm{A}$ and $\mathrm{C}$, whereas there was no difference in the trends between sites $\mathrm{A}$ and $\mathrm{C}$. These results suggest that in site $\mathrm{B}$ the rate at which boys and girls were becoming sexually active was lower than the rates in the other sites. Also, there is a worrying finding in the control site, where girls are starting sex at earlier ages than before.

\section{Circumstances around first sex}

Table 18 describes some of the circumstances under which adolescents first have penetrative sex. In baseline and endline surveys, the majority of adolescents first have sex with a boy/girlfriend or a friend. Although there are significant differences over time between these

girls there was a much higher proportions reporting ever had sex $(50 \%)$ at the endline by those who had also been interviewed during the baseline than those who had not (41\%). 
two categories, these are probably due to differences in coding responses by interviewers than to actual behavioural changes. Of more relevance are the significant decreases in the proportions of adolescents, of either sex, first having sex with someone other than a friend or boy/girlfriend in the intervention sites (and the control site for girls). It was also found that between one-quarter and one-third of girls and boys had first sex with someone their own age; most boys had sex with someone younger and most girls with someone older. There is no change over time in this behaviour.

There are increasing proportions of girls (in sites A and C) and boys (in sites A and B) reporting that the first time they had sex it was wanted, as opposed to them being persuaded or forced. For girls in site A, there were also significant decreases in the proportions reporting persuasion or force, down overall from 39 percent to 11 percent; non-significant decreases were also found in sites B and C (from $34 \%$ to $23 \%$, and $43 \%$ to $34 \%$ respectively). Girls in site $\mathrm{B}$ were significantly more likely to report being sweet-talked after the intervention, however, again perhaps reflecting the emphasis in the school-based activities on abstinence.

Table 18: Circumstances for first penetrative sex among sexually active adolescents

\begin{tabular}{|l|c|c|c|c|c|c|}
\hline \multicolumn{1}{|c|}{ Respondents } & \multicolumn{2}{|c|}{ Sites A } & \multicolumn{2}{c|}{ Sites B } & \multicolumn{2}{c|}{ Sites C } \\
\hline & Baseline & Endline & Baseline & Endline & Baseline & Endline \\
\hline Boys & $\mathrm{N}=90$ & $\mathrm{~N}=135$ & $\mathrm{~N}=95$ & $\mathrm{~N}=91$ & $\mathrm{~N}=87$ & $\mathrm{~N}=140$ \\
Who with: & & & & & & \\
$\quad$ Friend/acquaintance & 15 & $31^{*}$ & 25 & $35^{*}$ & 24 & $36^{*}$ \\
$\quad$ Girlfriend & 59 & 56 & 60 & 59 & 64 & $46^{*}$ \\
$\quad 11$ & 8 & 1 & 5 & 7 & 5 \\
$\quad$ Relative & 15 & $6^{*}$ & 14 & $1^{*}$ & 5 & 14 \\
$\quad$ Other & 78 & $96^{*}$ & 73 & $91^{*}$ & 80 & 87 \\
Wanted & 13 & $2^{*}$ & 19 & $3^{*}$ & 7 & 3 \\
Sweet talked & 3 & 0 & 5 & 2 & 11 & 6 \\
Persuaded & 5 & 2 & 3 & 4 & 3 & 4 \\
Forced & & & & & & \\
& $\mathrm{N}=138$ & $\mathrm{~N}=225$ & $\mathrm{~N}=163$ & $\mathrm{~N}=162$ & $\mathrm{~N}=162$ & $\mathrm{~N}=291$ \\
Girls & & & & & & \\
Who with: & 52 & $36^{*}$ & 52 & $25^{* *}$ & 45 & $36^{*}$ \\
$\quad$ Friend/acquaintance & 18 & $58^{* *}$ & 19 & $68^{*}$ & 32 & $54^{*}$ \\
$\quad$ Boyfriend & 2 & 4 & 1 & 2 & 7 & 6 \\
$\quad$ Relative & 28 & $3^{* *}$ & 28 & $5^{*}$ & 16 & $4^{* *}$ \\
$\quad$ Other & & & & & & \\
Wanted & 32 & $64^{* *}$ & 43 & 40 & 34 & $45^{*}$ \\
Sweet talked & 29 & 25 & 24 & $37^{*}$ & 24 & 21 \\
Persuaded & 24 & $4^{*}$ & 17 & 10 & 28 & 24 \\
Forced & 15 & $7^{*}$ & 17 & 13 & 15 & 10 \\
\hline
\end{tabular}

Comparisons are between baseline and endline within each site

These levels of non-consensual sex suggest that there may be an underlying culture of accepting gender-based violence. To assess this possibility, adolescents were asked whether it was ever justifiable for a man to beat his wife or girlfriend. As shown in Table 19, explicit agreement with this statement was quite low in the baseline, although slightly higher among boys and among the older adolescents. Some quite dramatic and significant decreases in the 
proportions of adolescents supporting this view can be seen by the time of the endline survey, and in all three sites. As some of the largest changes were seen in the control sites this would seem to reflect a community-wide change in attitude rather than changes brought about by the interventions.

Table 19: Proportions of adolescents agreeing that it is ever justified for a man to beat his wife / girlfriend

\begin{tabular}{|l|c|c|c|c|c|c|}
\hline Respondents & \multicolumn{2}{|c|}{ Sites A } & \multicolumn{2}{c|}{ Sites B } & \multicolumn{2}{c|}{ Sites C } \\
\hline & Baseline & Endline & Baseline & Endline & Baseline & Endline \\
\hline Boys & & & & & & \\
$10-14$ yrs & 12 & $5^{*}$ & 8 & 3 & 16 & $2^{* *}$ \\
$15-19$ yrs & 14 & $6^{*}$ & 16 & $5^{*}$ & 17 & $5^{* *}$ \\
Girls & & & & & & \\
$10-14$ yrs & 8 & 4 & 3 & 4 & 6 & 4 \\
$15-19$ yrs & 10 & 7 & 8 & 5 & 15 & $3^{* *}$ \\
\hline
\end{tabular}

Comparisons are between baseline and endline within each site

\section{Preventive behaviours among sexually active adolescents}

The interventions were also intended to provide appropriate information and services to sexually active adolescents so that they could practise safer sex. Sexually active adolescents were asked about three determinants of safer sex: the number of partners; frequency of sex; and use of protection.

Evidence from the diagnostic study indicated that most adolescents have sex sporadically and often outside the context of a romantic relationship. Indeed, the proportions of sexually active adolescents having sex in the last six months were 37-43 percent of boys and 35-55 percent of girls, indicating that 'secondary abstinence' is the norm in these communities. Although there were no significant changes over time within the intervention sites, those directly exposed to either the community-based or school-based interventions did show significantly higher levels of secondary abstinence at the endline survey than those not exposed, suggesting that participation in these interventions does have an influence on secondary abstinence. For the vast majority of sexually active adolescents, regardless of gender or site, the median number of times they had sex in the last six months was 2-4 for girls and 2-3 for boys, and the number of partners in the last six months was one for girls and 1-2 for boys. These findings did not change over time ${ }^{21}$.

As most sexually experienced adolescents do not enter into sustained sexual relationships with a partner, and those that are sexually active are likely to have sex only a few times per year, not always with the same person and often in unplanned situations, it would seem somewhat unrealistic to expect them to use contraceptives or condoms each time. Indeed, as shown on Table 20, use of protection at first and last sex for girls ranged between $20-38$ percent and for boys between $12-41$ percent (as described in Appendix B, this was the variable used to calculate sample sizes for the older adolescent age group). Although the high 
levels of 'secondary abstinence' noted above are encouraging, it raises the problem of how to promote and facilitate preventive measures on the few occasions when adolescents do have sex.

Table 20: Proportions of sexually active adolescents reporting use of a contraceptive or condom at first and last sex

\begin{tabular}{|l|c|c|c|c|c|c|c|c|}
\hline & \multicolumn{2}{|c|}{ Sites A } & \multicolumn{2}{c|}{ Sites B } & \multicolumn{2}{c|}{ Sites C } & \multicolumn{2}{c|}{$\begin{array}{c}\text { School } \\
\text { intervention }\end{array}$} \\
\cline { 2 - 9 } & Baseline & Endline & Baseline & Endline & Baseline & Endline & Yes & No \\
\hline Total Boys & $\mathrm{N}=90$ & $\mathrm{~N}=135$ & $\mathrm{~N}=95$ & $\mathrm{~N}=91$ & $\mathrm{~N}=87$ & $\mathrm{~N}=140$ & $\mathrm{~N}=45$ & $\mathrm{~N}=321$ \\
First time & 12 & $23^{*}$ & 24 & 15 & 17 & 12 & $11^{* *}$ & 36 \\
Last time & 27 & 33 & 41 & $31^{*}$ & 27 & 27 & $31^{*}$ & 44 \\
\hline Total Girls & $\mathrm{N}=138$ & $\mathrm{~N}=225$ & $\mathrm{~N}=163$ & $\mathrm{~N}=162$ & $\mathrm{~N}=116$ & $\mathrm{~N}=291$ & $\mathrm{~N}=56$ & $\mathrm{~N}=622$ \\
First time & 20 & 22 & 23 & 28 & 28 & 23 & $36^{*}$ & 25 \\
Last time & 22 & $33^{*}$ & 26 & 31 & 21 & $38^{*}$ & $39^{*}$ & 30 \\
\hline
\end{tabular}

Comparisons are between baseline and endline within each site

Among the girls, no changes were found for use of protection at first sex, but at last sex there were significant increases in use in sites $\mathrm{A}$ and $\mathrm{C}$, with a non-significant increase in site $\mathrm{B}$. Among those girls exposed to the school-based intervention, there was a significantly higher level of use than those not exposed, suggesting that this intervention is also contributing to the general increase in use of protection by girls.

For the boys, however, the findings are not so encouraging. The only improvement was among boys in site A using protection at first sex, whereas in site B there was a significant decline in use of protection at last sex. Moreover, among those exposed to the school-based intervention there were large and significantly lower levels of use, at both first and last sex, than among those not exposed. Why the school-based intervention should be having such different effects on the girls and boys is not clear.

For those reporting use of a method for first and/or last sex, the vast majority of boys and girls used a condom, with a small proportion using the pill. The most widely cited source for the method, for boys and girls, was buying them from a shop/duka. This is unsurprising given that these are the most easily accessible sources of condoms, a criterion that seems to outweigh the fact that condoms can be obtained at no cost from public health clinics.

For those not using a method at last sex, a wide variety of reasons were given without one clearly predominating. Among the boys, a lack of knowledge about contraceptive methods and how girls get pregnant were the most widely reported reasons; the girls, who in addition mentioned unplanned sex as another reason, also reported these.

\section{Experience of reproductive health problems}

Table 21 describes the experiences reported by sexually active adolescents. Experiences of STI symptoms in the past 12 months are low, which may reflect the low levels of sexual activity. The only significant change was among boys in site B, although this site also had by far the highest level reported during the baseline. When asked whether they sought treatment 
for the symptoms, the results are not clear, with large differences between the sites and over time, which is probably a function of the small numbers involved.

Among the never married girls living in site B there was no change over time in terms of experiencing pregnancy, with about one quarter of sexually active girls reporting a pregnancy. In both intervention site A and the control site, however, large and significant reductions in pregnancy were reported over time ${ }^{22}$. Whether these differences can be attributed to the equivalent differences in the use of protection at last sex cannot be confirmed, but it certainly indicates the possibility of a strong association.

Table 21: Proportions of sexually active adolescents reporting experiences of reproductive health problems

\begin{tabular}{|l|c|c|c|c|c|c|}
\hline \multicolumn{1}{|c|}{ Respondents } & \multicolumn{2}{c|}{ Sites A } & \multicolumn{2}{c|}{ Sites B } & \multicolumn{2}{c|}{ Sites C } \\
\hline & Baseline & Endline & Baseline & Endline & Baseline & Endline \\
\hline Boys & & & & & & \\
Experienced STI symptom in 12 months & 5 & 5 & 15 & $6^{*}$ & 11 & 6 \\
Ever got a girl pregnant & 7 & 7 & 7 & 7 & 6 & 7 \\
Girls & & & & & & \\
Experienced STI symptom in 12 months & 5 & 9 & 6 & 7 & 7 & 4 \\
Ever been pregnant (never married only) & 31 & $17^{*}$ & 29 & 24 & 35 & $10^{* *}$ \\
\hline
\end{tabular}

Comparisons are between baseline and endline within each site

\section{Multivariate analysis: Interactions with Peer Educators}

Multivariate analyses were undertaken to consider the influence on key outcome variables of living in the study sites, and of exposure to and participation in KARHP activities. These analyses confirmed all of the key findings presented above, and so to avoid repetition, and because of the complexity of these statistics, the findings will not be presented here.

A multivariate analysis was also undertaken to assess the effect of adolescents interacting with a peer educator. This analysis was important, as peer educators were a major component of all three interventions, and approximately one quarter of all adolescents in the four experimental Locations reported receiving information from a peer educator. The following findings emerged from the analysis:

- Adolescents in site A who met with a peer educator were more likely to have had sex in the last six months than those who did not meet with a peer educator in site B or those living in site $\mathrm{C}$.

- Adolescents who met with a peer educator were more likely to have heard about contraceptives and about condoms than at the baseline and than adolescents who did not meet with a peer educator. This was even more likely for adolescents meeting peer educators in site A.

- Adolescents who met with a peer educator were more likely to approve of condoms use by adolescents than at the baseline. 
- Sexually active adolescents who met with a peer educator were more likely to have used a condom at first or last sex compared with the baseline and with adolescents who did not meet with a peer educator.

- Female adolescents who met with a peer educator were less likely to report having been pregnant than at the baseline.

- Adolescents who met with a peer educator were more likely to discuss reproductive health issues with their parents than at the baseline and than adolescents who did not meet with a peer educator.

- Adolescents in site A who met with a peer educator were more likely to know when a woman could get pregnant than at the baseline and than adolescents in other sites.

These findings indicate that the peer educators did play an influential role, and in particular among the older and/or sexually active adolescents. Meeting with a peer educator appears to be associated with adolescents practising safer sex, as indicated by the increased likelihood of knowing about, approving of and using condoms, as well as the reduced likelihood of being pregnant. It is also associated with discussing reproductive health issues with parents and knowing about the fertile cycle. Although earlier (Table 7), it had been shown that adolescents in site $\mathrm{B}$ were more likely to report receiving information from a peer educator (probably because of the combination of school and community-based educators), it was the educators in site A that appear to have played a more important role.

\section{Costs and cost-effectiveness of the interventions}

The total cost of the three intervention components for the two and a half years of planning, introduction and implementation was approximately 12 million Kenyan shillings, or $\$ 154,374^{23}$ (see Table 22). About 4 million shillings was spent in site A and 8 million shillings in site B, because of the school-based intervention. Of the three interventions, the school-based intervention had the highest overall costs and the highest costs in all project phases. These costs were incurred over a period of approximately two years.

The single activity with the highest costs (over 55 percent of the total) was supervision and monitoring during the activity implementation and monitoring phase (which lasted approximately 12 months). This is because PATH staff travelled to the field frequently to work out implementation issues as they arose and to motivate staff. During this phase, the costs for PATH personnel and for transportation were high.

Training was the second most costly activity when the three categories are aggregated: training of trainers (TOT), training of clinicians, social and religious leaders and teachers, and training of peer educators. The training of clinicians, social and religious leaders and teachers accounted for the highest proportion, although these are dominated by the costs of training teachers, and consequently the costs for training personnel are higher in area B. Although the largest number of personnel trained were peer educators, the costs of their training are lower than for other personnel for two reasons: PATH personnel were actively involved in training sessions for the TOT and for the higher-level personnel, but not for the peer educators, and their costs are higher than those of trainers from the ministries. Second, there were no non-monetary costs associated with training peer educators because they are not ministry employees and their costs of attending the training sessions were not included. 
No costs for implementing the clinic-based services are included in either site because the clinic staff did not record any time spent on KARHP activities during the implementation phase. This undoubtedly represents some level of under-reporting by the clinic staff, but it should be noted that the CDAs, and not the clinic staff, supervised the peer educator activities at the clinics, and that there appears to be no increase in the number of reproductive health visits by adolescents. This suggests that clinic staff did not provide many services beyond what they normally provide.

The overall activity implementation costs are higher in site B, primarily because the schoolbased activities were undertaken here and not in site A. The reported costs of implementing the community-based activities were much higher in site B than in site A, even though there was only one active CDA in site B compared with two in site A. The reason for this is the higher level of non-monetary costs associated with the CDAs' time, because the one active CDA in site B was extremely dynamic. She worked closely with the religious leaders in her own location as well as in the other three locations, both in sites A and B.

It is important to emphasise that the cost of sustaining and scaling-up these activities will depend on who does it and the mix of activities that are to be sustained and scaled up. The costs of developing and implementing the interventions within the framework of this OR study were dominated by the costs of the technical assistance provided by personnel from PATH, who were involved in all stages of the project. If, as would be expected in any scaling-up exercise, the three ministries take over most or all of the responsibilities for planning and implementing these activities, then the costs for the first two phases would be substantially lower than the $\$ 68,000$ incurred during this project.

A second consideration is that costs will be lower for sustaining and scaling-up because not all of the development and planning activities need to be carried out again. The interventions themselves, including the training programmes, educational curricula, and IEC materials, have already been designed and so costs will be incurred in their replication only.

Most of the training costs will be incurred each time these activities are introduced into new areas. In the early stages of sustaining and scaling-up, it may be possible for the master trainers to be used for this training, thereby eliminating this cost, but for the longer-term expansion some TOT costs would need to be incorporated. The training costs for ministry staff, however, could be pro-rated over a period longer than the 18 months of this OR project for which the skills were used, thereby reducing the overall training costs. The costs for training peer educators could be reduced if they could be motivated to stay and contribute longer, although as adolescents looking to enter the job market it is unlikely that long-term retention of peer educators would ever be feasible.

The third phase of the project, which included implementation of the activities and their monitoring and supervision, is dominated by the costs of supervision and monitoring by PATH personnel. For sustainability and scaling-up, ministry personnel would need to take over these functions as part of their regular job responsibilities. As the costs associated with PATH personnel are higher than those for ministry personnel, and because supervision and monitoring had to be much more intense while piloting these new activities, it is expected that these costs would be much lower when the activities are sustained and expanded than the $\$ 86,000$ incurred here. 
Table 22: Estimated Costs by Area, Intervention, Activity and Phase of Project in Kenyan Shillings

\begin{tabular}{|c|c|c|c|c|c|c|c|c|c|}
\hline \multirow{2}{*}{ Activities } & \multicolumn{3}{|c|}{ A } & \multicolumn{4}{|c|}{ B } & \multirow{2}{*}{$\begin{array}{c}\text { Total } \\
\text { (Kshs) }\end{array}$} & \multirow{2}{*}{$\begin{array}{c}\text { Total } \\
\text { (US\$) }\end{array}$} \\
\hline & Clinic & Community & Total & Clinic & Community & School & Total & & \\
\hline \multicolumn{10}{|c|}{ Phase I - Planning } \\
\hline Preparatory Meetings and Other Planning Activities & 608,689 & 31,735 & 640,424 & 597,701 & 31,715 & 965,099 & $1,594,515$ & $2,234,939$ & 28,653 \\
\hline \multicolumn{10}{|c|}{ Phase II - Training and introduction of interventions } \\
\hline Training of Trainers & 151,685 & 151,685 & 303,370 & 151,685 & 151,685 & 151,685 & 455,055 & 758,425 & 9,723 \\
\hline Training of Intervention Personnel & 127,966 & 171,042 & 299,008 & 126,981 & 167,828 & 599,875 & 894,684 & $1,193,692$ & 15,304 \\
\hline Training Peer Educators & 23,937 & 62,237 & 86,174 & 23,937 & 62,237 & 478,749 & 564,923 & 651,097 & 8,347 \\
\hline Modifications to Improve Clinics' Youth-friendliness & 232,500 & 0 & 232,500 & 232,500 & 0 & 0 & 232,500 & 465,000 & 5,962 \\
\hline Subtotal & 536,088 & 384,964 & 921,052 & 535,103 & 381,750 & $1,230,309$ & $2,147,162$ & $3,068,214$ & 39,336 \\
\hline \multicolumn{10}{|c|}{ Phase III - Implementing activities and monitoring } \\
\hline Supervision and Monitoring & $1,256,566$ & $1,234,741$ & $2,491,307$ & $1,246,639$ & $1,234,741$ & $1,255,517$ & $3,736,897$ & $6,228,204$ & 79,849 \\
\hline Activity implementation & NA & 31,708 & 31,708 & NA & 180,508 & 297,595 & 478,103 & 509,811 & 6,536 \\
\hline Subtotal & $1,256,566$ & $1,266,449$ & $2,523,015$ & $1,246,639$ & $1,415,249$ & $1,553,112$ & $4,215,000$ & $6,738,015$ & 86,385 \\
\hline Grand total & $2,401,343$ & $1,683,148$ & $4,084,491$ & $2,379,443$ & $1,828,714$ & $3,748,520$ & $7,956,677$ & $12,041,168$ & 154,374 \\
\hline
\end{tabular}

$\$ 1=78$ Kenyan Shillings 


\title{
SUMMARY AND CONCLUSIONS
}

This study produced a wealth of information, and so a summary of the key findings from the evaluation of the interventions is given in the following boxes. In brief, the three ministries, with strong technical support and leadership from PATH, successfully implemented the three interventions. This level of activity ensured that the KARHP Project was not only well known (even in the control site), but also that significant proportions of adolescents and parents participated in one or more activities. As would be expected, the health facility-based activities were not widely used, and given that the cost of this intervention was 1.5 times as much as the community-based intervention, it is questionable whether investing in making clinics youth-friendly is a cost-effective strategy. This study confirmed that the different peer educator models tested here were successful in reaching adolescents, especially with information. As with all peer educator programmes, however, their sustainability over time is likely to be limited, and so it will be important to monitor how well they have functioned since the end of KARHP.

The study showed some mixed results in terms of increasing awareness and knowledge about reproductive health issues. Adolescents in all intervention sites were more likely to receive reproductive health information, and so clearly this multi-sectoral approach is reaching adolescents with this information. However, some differences were found between site A and site $\mathrm{B}$, indicating that the addition of the school-based intervention in site $\mathrm{B}$ did have some effect. Given that the community-based intervention was more intensively implemented in site A than site B, however, care is needed in interpreting the findings. For example, parentchild communication on reproductive health issues increased significantly in site A for all except the younger boys, which indicates that the community-based activities definitely contributed to this improvement. Whether it was because of the greater intensity of the activities in site A (which had two CDAs compared with one in site B, and consequently more community-based peer educators), or because the school-based activities encouraged adolescents to talk more with their teachers than their parents, is not clear.

The school-based intervention appears to have raised awareness of basic sexual and reproductive health functions among all adolescents except older boys. Although awareness of contraception increased significantly in site A only, suggesting that the school-based intervention did not add to this, direct exposure to both the community-based and the schoolbased interventions significantly improved awareness. Knowledge of specific methods increased in all three sites overall, suggesting that the interventions are not having an effect beyond other activities in the areas. Knowledge of specific STIs was higher in both intervention sites than in the control site, however, indicating that this important information is being communicated through the interventions. None of the interventions were able to improve either the poor knowledge of how to use the condom, or the fertile cycle in a woman.

\begin{abstract}
Abstinence as a preventive behaviour is clearly being well communicated through both community and school-based interventions. Using the condom for prevention is now better known among girls and boys in site A and among girls in the control site, but not among adolescents in site B, which suggests that the school-based intervention may be diluting the effect of the messages being communicated generally in the districts and specifically through the community-based activities. Some increases in awareness of preventive behaviours were found in the control site for parents, but as those living in Site A also showed large increases in awareness of all behaviours, it would seem that the community-based activities are influencing the parents.
\end{abstract}




\section{Key Findings}

\section{Exposure to the interventions}

- Almost half of all parents and adolescents had heard of KARHP in the two intervention sites (two-thirds of adolescents in site B had heard of KARHP). Onefifth of adults and adolescents in the control site had heard of the project, despite no activities being carried out there.

- One-fifth of all parents had ever participated in an activity, and over one-third of adolescents in site B.

- Less than 10 percent of adolescents participating in a KAHP activity participated in a health facility-based activity.

- One-quarter of all adolescents in all intervention sites had ever received information from a peer educator.

\section{Knowledge of reproductive health issues}

- Awareness of basic sexual and reproductive health functions improved substantially among younger adolescents, and for some issues among older girls, in intervention site $\mathrm{B}$.

- Adolescents in the intervention sites were much more likely to have received any reproductive health information in the past year than those in the control site.

- Parent-child communication improved with all girls and older boys, but only in intervention site A.

- Awareness of contraception improved among all girls and younger boys, but only in intervention site A. Direct exposure to the community-based or school-based interventions significantly increased levels of awareness.

- Among those adolescents who were aware of contraception, large increases in knowledge of condoms, pills and injectables were found across both intervention and control sites.

- Awareness of specific STIs among all adolescents was significantly higher in both intervention sites than in the control site at the endline survey.

- Girls and boys better know abstinence as a preventive behaviour in both intervention sites. Condom use is better known in intervention site $A$, but also among girls in the control site.

- Parents in site A showed large increases in awareness of all preventive behaviours, whereas in site $B$ there was increased awareness of being faithful but significant decreases in asking the partner to be faithful. Increases in awareness of preventive behaviours (some of which were significant) were also found in the control site.

- Knowledge of a woman's fertile period remained very low, even after the interventions. 


\section{Attitudes towards adolescent sexuality and reproductive health}

- Disapproval of premarital sex and childbearing was high to begin with, and the interventions (especially in site $A$ ) have reinforced these attitudes, including the higher levels of disapproval for females. However, premarital sex was the norm among the parents and so is not a recent phenomenon as often portrayed.

- Among boys in site $B$, there was no increase in approval of contraceptive and condom use. For boys in site A and the control site, however, approval increased, and in most cases significantly.

- Among girls, approval of condom use by adolescents increased in both intervention sites, and of contraceptive use by married couples in site A and the control site.

- For those adolescents directly participating in the school-based activities, however, approval of contraceptive and condom use is significantly lower than for all other adolescents.

\section{Sexual behaviour}

- $59-72 \%$ of boys and $76-84 \%$ of girls report never having undertaken any type of sexual activity at all (including kissing and touching). Among those reporting sexual experience, very few have practised kissing or touching, with penetrative sex being the norm.

- A significant increase among older girls and boys reporting penetrative sex was observed in site A and in the control site, and a significant reduction was observed among boys in site $B$.

- For those adolescents directly participating in the school-based activities, reported experience of all types of sexual behaviour is significantly lower than for other adolescents not exposed to the school-based intervention.

- Age at first sex among the sexually experienced showed statistically significant delays after the interventions among boys in sites $A$ and $B$ and among girls in site $B$. No change was found in the control site.

- The rate of increase in the proportions of boys and girls becoming sexually active as they get older was significantly lower in site $B$ than in sites $A$ and $C$ at the endline.

- The proportions of girls in all sites, and boys in the intervention sites only, first having sex with someone other than a close friend decreased significantly.

- The proportions of girls indicating non-consensual sex decreased over time in all three sites, and significantly in site A. Girls in site B are now much more likely to report being sweet-talked.

- Secondary abstinence remains very common, with one half to two thirds of sexually active girls and boys not having sex in the previous six months, but there was no change over time in any sites.

- Use of a contraceptive or condom at first and last sex remains rare, although there were significant increases in use at last sex among girls in site $A$ and the control site, and among girls participating in the school-based activities. There were decreases in use at first and last sex, however, among boys in site B and especially among those participating in the school-based activities.

- For those using a method, the vast majority use a condom and buy them from shops/dukas.

- There were decreases over time in the proportion of unmarried girls reporting ever been pregnant, and these were significant in site $\mathrm{A}$ and the control site. 
Attitudes regarding premarital sex and childbearing in all sites remained conservative, indicating that the interventions not only did not challenge these, but also probably reinforced them. This is despite the tradition of premarital sex that exists and continues in these communities. Additionally, however, approval of contraceptive and condom use improved in both the control site and site A, suggesting that the school-based intervention in site B has reinforced existing disapproval of contraceptive and condom use, countering general trends towards approval.

It was not anticipated that the ultimate goals of reducing early sexual debut and increasing safer sex could realistically be addressed within the short period of time the project was underway, but the results do show some encouraging signs in these directions. It is important to emphasise that the level of reported sexual activity among adolescents at the start of the study was not particularly high. The proportion of older adolescents reporting ever having had penetrative sex increased over time in site A and the control site, but actually reduced for older boys in site B. However, there was a significant delay in the age of first sex, particularly among girls and boys in site B and among those participating in the school-based interventions. Moreover, the majority of those who reported being sexually active had sex infrequently and with few partners - secondary abstinence remains the norm for the sexually active.

Decreases in reporting of non-consensual first-time sex, together with an increased likelihood of first having sex with a friend rather than someone else, are encouraging indications of less dangerous practices. Although the proportions of sexually active adolescents using protection remains low, some improvements among boys at first sex and girls at last sex were found in site A (and also for girls participating in the school activities and those living in the control site), which gives hope for the future. Protection was primarily through using the condom, a dual protection behaviour which adolescents should be encouraged to sustain or reinforce with the pill or injectable, rather than switching to the injectable or pill alone. Declines in pregnancy among unmarried adolescents also support the possibility of the start of a trend towards safer sexual behaviour, at least among girls.

In interpreting these findings it is important to highlight the dramatic changes that were occurring within Kenya during the time of this study. Over the past five years, the amount of energy and resources allocated to addressing adolescent reproductive health issues has increased tremendously, with the Government and development partners recognising these as national priorities. All three ministries that participated in this study also independently developed other initiatives to improve adolescents' situation, at both the provincial and national levels. For example, the 'Adolescent Reproductive Health and Development' Policy was being developed over this period (and was launched in September 2003), the Ministry of Education launched a schools-based HIV/AIDS education curriculum and campaign, the Children's Act was passed in 2001, and many technical assistance organisations have been piloting innovative small-scale adolescent reproductive health projects.

As can be seen from these findings, a few changes occurred in the control site that may reflect these other activities: increased awareness of specific contraceptive methods; knowledge that condom use and other behaviours can prevent HIV transmission; approval of condom use among boys; and increased condom use by girls. However, both intervention sites showed significant changes in many key indicators, which suggests the communitybased and school-based activities have had many additional impacts. Most importantly, these include: increasing the amount of information available and awareness of reproductive health issues; maintaining and strengthening attitudes favouring promotion of abstinence and fidelity, while also improving attitudes towards practising protected sex; and commencing a 
delay in sexual initiation (especially among those participating in the school-based activities) and encouraging safer sex practices (especially among girls, and among girls participating in the school-based activities).

In using these findings to inform programme planning, it is essential that each ministry pay close attention to the specific effects that each intervention was able, and just as importantly was not able, to achieve. Moreover, it is important that the costs of implementing each set of activities are considered in relation to what they have achieved so that only cost-effective activities are promoted for further replication. 


\section{APPEndix A: DeVeloping AND IMPLementing the INTERVENTIONS}

\section{Preparation and sensitisation}

PATH and FRONTIERS invested much effort in preparing the ground for introducing the KARHP activities. At the national level, the three ministries were involved in the design of the interventions and every effort was made to ensure that they understood the nature, purpose and design of the project, although initially the partners had problems appreciating the value of a quasi-experimental design. For transparent and effective management of the project, the five partners - with PATH as team leader - formed the Project Implementation Team (PIT). Two persons from each ministry were involved to enable representation in all meetings and site visits. The Department of Social Services was not involved in the initial discussions but joined the project during the launch of the community interventions when their representative recommended that the project should work with their district and divisional staff.

During the first quarter of the project, the PIT members continued to meet with staff from the three ministries and to make final arrangements for the launch of the project. Meetings were held with each health facility's health management committee, sponsors of schools, religious leaders and parents to seek their support to launch the project in their localities. It was during these meetings that the project received overwhelming support from the Catholic Church, which had previously been perceived as an opponent. Mapping and diagnostic research was conducted to understand the services available and community concerns and solutions. These results informed the project's baseline survey, as well as the design of interventions. The design of the interventions were finalised by the PIT members during a two-day workshop in June 2000, although the interventions continued to be revised and adapted throughout the project to address emerging issues and opportunities.

\section{Training}

\section{Development of training manuals}

The training process began with the development of separate manuals by PATH for training health workers, schoolteachers and peer educators. The contents of the manuals were grounded in the nine basic modules agreed upon by the overall FRONTIERS global youth study:

- Human anatomy/physiology, puberty and maturation

- Relationships, including romantic relationships

- Values clarification, including self efficacy, aspirations and negotiation skills

- Sexual behaviour, including intimacy, forms of sexual expression and sexual satisfaction

- Gender issues, including sexual violence (rape, molestation, defilement and any form of sex abuse) and how to prevent it, and gender discrimination or differences

- Negative consequences/risks of sexual behaviour, including loss of relationship and reputation, guilt, family disapproval, unintended pregnancy and STI 
- Motivation of sexual behaviour, including desiring pregnancy, desiring intimacy, and maintaining relationships

- Protective behaviour, including condom use, having one partner and abstinence

- Resources for youth (list of reference materials and places adolescents can visit for various services)

The manual for training health providers focused on youth-friendly attitudes and skills, whereas the manuals for school teachers and peer educators focused more on increasing knowledge, changing attitudes and providing skills to adopt safer sexual practices. The manual for training school teachers was also used to train peer educators and to expose inschool youth to sexual and reproductive health issues. The manual was organized around 34 one-hour sessions (see below) that could be implemented as a curriculum in a school context.

\begin{tabular}{|c|c|c|c|}
\hline \multicolumn{4}{|c|}{ Module One: Adolescent Development } \\
\hline Session 1: & Adolescence & Session 19: & Verbal Communication \\
\hline Session 2: & Reproductive System - Male & Session 20: & Listening \\
\hline Session 3: & Reproductive System - Female & Session 21: & Self-Esteem \\
\hline Session 4: & $\begin{array}{l}\text { Myths and misconceptions about } \\
\text { reproduction }\end{array}$ & $\begin{array}{l}\text { Session 22: } \\
\text { Session 23: }\end{array}$ & $\begin{array}{l}\text { Self-Esteem Continued } \\
\text { Assertive Skills }\end{array}$ \\
\hline Module Two: & Human Sexuality & Session 24: & Assertive Skills Continued \\
\hline Session 5: & Sexuality & Session 25: & Decision-making \\
\hline Session 6: & Sexuality and Behaviour & Session 26: & Setting Goals \\
\hline Session 7: & Sexual Exploitation & \multicolumn{2}{|c|}{ Module Six: Teenage Pregnancy And Abortion } \\
\hline Session 8: & Rape & Session 27: & Teenage Pregnancy and Abortion \\
\hline \multicolumn{2}{|c|}{ Module Three: Gender } & \multicolumn{2}{|c|}{ Module Seven: Sexually Transmitted Diseases } \\
\hline Session 9: & Introduction to Gender & Session 28: & Sexually Transmitted Infections \\
\hline Session 10: & Gender Stereotypes & Session 29: & HIVIAIDS \\
\hline Module Four: & Relationships & Session 30: & Facts and myths - STIs/ HIVIAIDS \\
\hline Session 11: & Types of Relationships & \multicolumn{2}{|c|}{ Module Eight: Preventive Behaviours } \\
\hline Session 12: & Friendship & Session 31: & Methods of Contraceptive \\
\hline Session 13: & Boy/Girl Relationships & Module Nine: & : Drug Abuse \\
\hline Session 14: & Love and Infatuation & Session 32: & Drug Abuse \\
\hline Session 15 & Parenthood & Session 33: & Resisting Peer Pressure \\
\hline Module Five: & Life Skills & Module Ten: & Resources \\
\hline Session 16: & Values & Session 34: & Resources For Adolescents \\
\hline Session 17: & Communication & Session 35: & Record Keeping \\
\hline Session 18 & Non-verbal Commun & & \\
\hline
\end{tabular}

\section{Training of project personnel}

The basic training was undertaken August - December 2000, but additional training continued intermittently throughout the project. Trainers were drawn from the three ministries and oriented by PATH staff and consultants through training of trainer sessions. The trainers conducted all the subsequent training activities under supervision of the PIT including training of additional teachers, head teachers, health workers, peer educators and the religious leaders. A training strategy using a thematic approach was developed. 


\section{Training of health facility service providers}

District clinical officers and the public health nurses from Busia and Vihiga selected the service providers for training using criteria presented to them by the PIT, which included: experience in adolescent service delivery; participation in youth development activities; willingness to perform volunteer work; age less than 40 years; flexibility and patience with young people; existence of a positive attitude towards adolescents and their sexual health; and a good understanding of adolescent reproductive health. In addition, those doing the selection were encouraged to ensure a gender balance but this was not possible as women staffed most facilities.

Of the 50 service providers identified, 38 participated in the training representing 16 of the 19 public and private facilities in four locations and included one medical doctor, four clinical officers and 33 nurses. The trained $\mathrm{MOH}$ trainers, with support from PATH, facilitated the training. The course content included the following: STI/HIV/AIDS; needs and concerns of adolescents; contraceptive update; sexuality and adolescent sexual behaviour; values; communication; counselling; use of visual aids; record keeping; and development of action plans. Pre- and post-tests were conducted at the beginning and end of the training, and demonstrated that trainees had increased their knowledge.

The service providers developed plans of action indicating what they would do to improve the quality and friendliness of their services. Neighbouring private and public facilities worked together in this exercise. Some of the highlights in their plans included debriefing medical or clinical officers in charge of the facilities; holding awareness-raising meetings with staff in all facilities; debriefing the local health centre/clinic committees; identifying and allocating a room for youth activities; refurbishing and upgrading youth rooms; forming project local advisory committees; recruiting health-facility based peer educators and facilitating their training. The health providers also promised to submit monthly written reports to the project's field coordinator and to strengthen the community outreach medical services with a specific focus on youth.

\section{Training of school teachers}

PATH and the MOEST trained six trainers who then trained guidance and counselling teachers, who then trained peer educators. The education officials in Wodanga and Nambale locations were presented with the following selection criteria by the PIT to identify teachers for training:

- Involvement in youth activities such as sports, drama, debates and scouting

- Aged at least 30 but not more than 40 years

- Willingness to carry out work on voluntary basis

- Willingness to implement an in-school FLE (Family Life Education) program

- Some level of understanding of adolescent reproductive health

- A positive attitude towards adolescent health and sexuality

The trainers (education officers and supervisors) trained the teachers for one week with support from PATH and the MOEST headquarters. During training, emphasis was placed on the use of participatory methodologies in health education. Teachers were also trained on how to use peer education approaches to increase young peoples' understanding of reproductive health and to promote better health behaviours. 
In all training sessions pre- and post-tests were conducted and all trainees showed improvements in their knowledge. At the end of the two initial training workshops for schoolteachers, participants worked in groups to develop plans of action. The key highlights of the action plans included debriefing head teachers; conducting orientation meetings for all staff and school committees; advocating for allocation of a guidance and counselling room; advocating for allocation of an hour per week in the schools timetable to be used for FLE sessions; discussing the project with adolescents of 10-19 years; identification and recruitment of qualified youth to be trained as peer educators; spearheading the formation of health clubs; coordinating health club activities and submitting progress reports to area schools inspectors.

\section{Training of peer educators}

The CDAs and schoolteachers identified peer educators to participate in the project using criteria developed by the PIT: aged 10-20 years; role model or influential among peers; active in schools and/or community activities; interest in adolescent health; interest in volunteer work and willingness to avail time to educate other youth. The CDAs worked closely with the local religious groups, youth groups and local administration to identify well-mannered and motivated youth to be trained as health facility-based peer educators. In some communities, the same peer educators distributed condoms to other youth.

Most schools identified between 30 and 40 peer educators. The in-school and out-of-school peer educators were trained between October and December 2000. The 11 trained trainers from both MOH and MOEST participated in training of peer educators to ensure that appropriate methodologies were used and correct information passed on to the participants. There were four training centres for the out of school peer educators, while each school trained their own peer educators. PATH project staff closely monitored all the training to ensure that they were conducted satisfactorily. Training of additional in and out-of-school peer educators happened at a later time in the project, a result of attrition. The trained peer educators received continuous training using PATH's thematic approach.

It was anticipated that several of the out-of-school peer educators would drop out and many of the in-school peer educators would graduate, and so the project continued to recruit new peer educators and sought to ensure that the existing ones were properly trained and motivated.

\section{Thematic approach to training project personnel}

To maintain a high level of motivation and to ensure the quality of information that passed from trainers to peer educators, PATH developed a continuous training and orientation methodology that focused on key themes, such as sexual violence, pregnancy prevention and sexually transmitted infections. Every month peer educators met to undergo a short training course on one aspect of a theme that was running continuously for two to three months. During this time, trained school teachers, service providers and CDAs selected topics from the themes to be addressed at each training session, and the PATH field coordinator monitored the training sessions and provided relevant materials as the need arose.

Other staff undertook the thematic short courses on a bi-monthly basis. Project trainers and PATH personnel facilitated the sessions, which lasted about six hours. Some of the themes discussed included: sexual abuse and pregnancy prevention, sexually transmitted infections including HIV and AIDS, communication and assertive skills. After the sessions participants were given handouts that focused on particular aspects of the running theme. The educators used a series of handouts named "Educator Updates" as discussion guides and reference materials. 


\section{Implementation of project interventions}

Upon completion of training, activities were launched at community, school and healthfacility levels. During the training participants developed work plans indicating activities they expected to conduct within the next three months. The work plans formed the basis for the trainees' initial activities when they returned to their workplace or homes.

\section{School-based activities}

The trained schoolteachers debriefed their head-teachers and committee members. They discussed what KARHP was about, its objectives and activities. They held similar meetings with the entire teaching staff and informed the student community of the project. These meetings were aimed at increasing understanding of the project and to solicit school personnel support. This was found to be crucial because of the controversies regarding sexuality education in schools. The trained teachers had to explain that KARHP was not about sex but reproductive health education.

The trained teachers embarked on a recruitment drive for suitable students to be trained as peer educators. They introduced and launched health clubs (also called KARHP clubs in some schools). Many students were interested in becoming peer educators and club members. As a result, a number of schools reported that they had to turn down interested students to keep the number to 30, but some schools went ahead and trained more than 30 students.

The trained teachers started to implement the 34-hour curriculum. Due to differences in administration, each school devised its own approach for exposing the students to the curriculum. In most schools, the sessions were held after school hours with individual or combined sessions, while others used 'club' and lesson times available for non-examinable subjects, such as physical education, to do so.

The schools launched health clubs with trained peer educators as pioneer members. The club members immediately embarked on campaigns to educate their schoolmates through group and one-on-one meetings. With the assistance of trained teachers, the peer educators begun to compose songs, poems, and skits for use during group education sessions. They received communication materials from PATH to enhance their group education sessions. The peer educators referred their colleagues to the guidance and counselling teachers and youthfriendly service providers. The teachers also helped to organize debates focusing on various reproductive health topics.

Guidance and counselling for students was the other key responsibility of the trained teachers. After training, the teachers made arrangements with their head teachers to identify and set aside a room where students could be counselled. Virtually all schools were successful in allocating a room, even though some schools had very limited space. This was a sign of commitment and support for the project. Throughout the project, the teachers provided guidance and counselling to their students and referred cases they could not handle to other teachers and trained service providers.

Every two months, all project teachers met to plan together and share experiences. Their meetings were useful in encouraging schools that lagged behind in their activities. The sharing encouraged all schools to try new ways of intensifying their education and outreach activities.

\section{Health facility-based activities}

After training, service providers held meetings with the health centre management committees and staff (private facilities had briefing meetings with their staff) to inform them about the project and solicit support for its implementation. The other health facility staff 
were also given an orientation on 'providing quality and youth-friendly services' by their trained colleagues. The project coordinator and project trainers participated in these sessions and offered support. The fact that only trained providers would treat young people in a friendly manner was a concern to the project, but as it was not possible to train all the providers at once it was agreed that all health providers - including support and paramedic staff - be brought on board through an orientation. The health management committees and staff of health facilities supported the project, resulting in requests to train more service providers to increase young people's access to friendly services.

In the four public facilities, the health management committees allocated rooms, which were refurbished and converted into a "youth-friendly" room. Adolescents who needed confidential services could visit these rooms and discuss their needs with a peer educator before being referred to the health provider. With the help of the youth-friendly providers, the peer educators organized health centre in-reach meetings where youth came together to discuss their sexual health concerns and receive confidential services. They also organized video shows on a wide range of health issues.

The project installed directional signposts indicating the services available for all 19 health facilities. The signposts were situated at strategic locations and helped to direct the youth to the health facilities.

\section{Community-based interventions}

Trained health care providers conducted training for out-of-school peer educators. A total of 132 adolescents were initially trained as peer educators to work at health facilities and in the community. The peer educators operating at the community level were coordinated and supported by the CDAs. The peer educators conducted individual and group discussions with their peers; visited and carried out educational activities in churches; visited youth groups; distributed condoms and made referrals to health facilities. Peer educators made efforts to promote proper use of condoms through discussions and demonstrations. Both the health facility and community-based peer educators used drama, songs and poems to increase their education and outreach. Peer educators used various IEC materials to educate and discuss sexual and reproductive health issues with their peers. These included videotapes, booklets, leaflets, fact sheets, game boards and guides for developing skits. They also organized sports activities for out-of-school youth as opportunities to communicate appropriate messages.

Religious leaders discussed with their congregations adolescent sexual and reproductive health issues. They received information and communication skills to enable them to talk to their congregations. Apart from speaking openly about these issues to their congregations, the religious leaders organized inter-denominational rallies for youth and parents and invited project personnel as well as other experts to discuss various health concerns. The religious leaders also organized group meetings within their churches or mosques and invited peer educators, social development assistants and youth-friendly peer educators to talk.

\section{Project monitoring and supervision}

The PIT designed tools and planned all monitoring activities, although the project coordinator and principal investigator were responsible for providing overall monitoring responsibility for the project. The PIT members visited the project on a quarterly basis, the principal investigator visited every month and the coordinator monitored on a weekly basis. In addition, the project trained 12 district-level individuals from MOEST, MOH and the Department of Social Services to supervise the teachers, health workers and peer educators. The supervisors were expected to visit once a month and submit reports to the field coordinator. 


\section{APPEndiX B: SAMPLing StRATEgies}

\section{Sample size calculations}

\section{Adolescents aged 10-14 years}

The main objective of the interventions for the 10-14 year olds was to delay age at first sex. To estimate the sample size for adolescents aged 10-14 years, baseline estimates for this variable were derived from a 1999 youth survey conducted by GTZ in Vihiga district, which indicated that $16.7 \%$ of girls and $39 \%$ of boys in this age group had ever had sex. The intervention was to be judged as successful if a decrease of 40 percent in the proportion of youth age $10-14$ years that had sex was achieved. Using an 80 percent power, a significance level of .05, and controlling for a design effect of 1.1 and 15 percent nonresponse rate, the sample size calculations using the following formula arrived at a total of 570 boys and 1,386 girls (190 boys and 462 girls per site):

$$
\mathrm{n}^{\prime}=\left(\mathrm{c} \alpha / 2 \sqrt{2} \Pi \mathrm{O}-\mathrm{C}_{1-\beta} \sqrt{ } \mathrm{P}_{1} \mathrm{Q}_{1}+\mathrm{P}_{2} \mathrm{Q}_{2}\right)^{2}
$$

$$
\left(\mathrm{P}_{2}-\mathrm{P}_{1}\right)^{2}
$$

Where: n' - Derived sample size required

$c \alpha / 2$ - Critical value in the standard normal curve, corresponding to the specified significance level (two tailed)

$\mathrm{C}_{1-\beta}-$ Critical value in the standard normal curve corresponding to specified power of the test

$\mathrm{P}_{1}$ - Proportion of members of the first group who possess the attribute or outcome being studied

$\mathrm{P}_{2}$ - $\quad$ Proportion of members of the second group which if actually found, would be deemed to differ sufficiently from $\mathrm{P}_{1}$

$\Pi$ - Mean of $\mathrm{P}_{1}$ and $\mathrm{P}_{2}$

$\mathrm{Q}_{1}$ - Proportion of the members of the first group who do not possess the attribute or outcome being studied

$\mathrm{Q}_{2}$ - Proportion of the members of the second group who do not possess the attribute or outcome being studied

$\mathrm{O}-\quad$ Mean of $\mathrm{Q}_{1}$ and $\mathrm{Q}_{2}$

\section{Adolescents aged 15-19 years}

The primary focus for this age group was to increase safer sex practices among the sexually active. As the GTZ survey did not include this age group, the 1998 Kenya Demographic and Health Survey (KDHS) was used, which indicated that among the sexually active (defined as having had sex in the last four weeks), 20.4 percent and 44.5 percent of unmarried females and males respectively, were currently using any modern contraceptive method (mostly condoms). The intervention would be judged to be successful if an increase of 40 percent in the proportion of sexually active youth age $15-19$ years currently using a modern 
contraceptive method is achieved. Using these figures, a sample size of 426 boys and 1452 girls ( 484 girls and 142 boys per site) both at the baseline and endline surveys was calculated using 80 percent power, a significance level of .05 , a design effect of 1.1 , and a response rate of $85 \%$.

\section{Parents/Guardians}

For the parents, "support for youth to receive RH services" was the key variable used to estimate the desired sample size. According to the $1998 \mathrm{KDHS}, 52$ percent and 68 percent of female and male respondents, respectively, believe that FP services should be available to youth less than 18 years of age. Since the intervention activities for reaching parents were not as intense as for the adolescents, the interventions were judged to be successful if a 25 percent increase in positive attitudes towards provision of services to youth was achieved. Calculations for this indicator using 80 percent power and 95 percent confidence level, and adjusting for a response rate of $80 \%$ and design effect of 1.1 , gives minimum samples sizes of 381 male and 897 female parents.

\section{Sample selection}

Multistage stratified and simple random methods were used to select individual adolescents and parents for interview. Twenty-one clusters in each Location were randomly selected from among the 1998 Census Enumeration Areas (EAs). Each cluster had approximately 100 - 120 households. All households were then listed and information regarding the number, sex and age of household members were collected and recorded on a screening sheet. Households with no adolescents aged 10-19 years were considered ineligible. All eligible households were then further categorised as being eligible for recruiting male or female respondents or both, and being eligible for the 10-14 year or 15-19 year group, or both. From each household the interviewers selected one adolescent from each age group for interview, randomly if there were more than one eligible adolescent. The required numbers of male and female respondents per site were randomly selected proportionate to the cluster size. For every fifth adolescent interviewed, a parent or guardian of the same sex was also interviewed.

\section{Sample weighting procedures}

The baseline probabilities of selecting adolescents are a product of the probability of selecting the sample EAs and the probability of selecting adolescents from each of the 'sex by age' group strata. The unconditional probability of selecting an adolescent into the baseline survey was:

$\mathrm{Pb}_{\mathrm{jjas}}=\left(21 / \mathrm{T}_{\mathrm{ij}}\right) *\left(\mathrm{n}_{\mathrm{jias}} / \mathrm{N}_{\mathrm{jias}}\right)$

Where:

$$
\begin{aligned}
\mathrm{T}_{\mathrm{ji}}= & \text { total number of EAs in the } \mathrm{i}^{\mathrm{th}} \text {-location }(\mathrm{i}=1,2) \text { in the } \mathrm{j}^{\text {th }} \text { intervention group }(\mathrm{j} \\
& \text { ranges from } 1 \text { to } 3: 1 \text { for experimental group } 1,2 \text { for experimental group } 2 \text { and } \\
& 3 \text { for control; } \\
\mathrm{n}_{\mathrm{jias}}= & \text { total sample of adolescents in the } \mathrm{i}^{\text {th }} \text { location in intervention group } \mathrm{j} \text { who } \\
& \text { belong to the stratum defined by age groups }(\mathrm{a}=1 \text { for } 10-14 \text { and } \mathrm{a}=2 \text { for } 15-19) \\
& \text { and sex ( } \mathrm{s}=1 \text { for female, and } \mathrm{s}=2 \text { for males); } \\
\mathrm{N}_{\mathrm{jias}}= & \text { total number of adolescents enumerated in the } \mathrm{i}^{\text {th }}{ }^{\text {th }} \text { location in intervention } \\
& \text { group } \mathrm{j} \text { who belong to the stratum defined by age groups and sex. }
\end{aligned}
$$

This probability of selection for the baseline survey was adjusted by multiplying the original probability of selection by response rates by subgroups. The inverse of the adjusted selection probability is the analysis weight. 
The endline sample was selected with the probability of:

$\mathrm{Pe}_{\mathrm{jias}, \mathrm{u}}=\left(21 / \mathrm{T}_{\mathrm{ji}}\right)^{*}\left(\mathrm{n}_{\mathrm{jias}}-\mathrm{n}_{\mathrm{jias}, \mathrm{b}}\right) /\left(\mathrm{N}_{\mathrm{jias}, \mathrm{e}}-\mathrm{n}_{\mathrm{jias}, \mathrm{b}}\right)$

Where $\mathrm{T}_{\mathrm{ji}}, \mathrm{n}_{\mathrm{jias}}, \mathrm{n}_{\mathrm{jias}, \mathrm{b}}$ are defined as above and $\mathrm{N}_{\mathrm{jias}} \mathrm{e}$ is the total number of adolescents enumerated during the endline survey in each of the $\mathrm{i}_{-}{ }^{\text {th }}$ location in the $\mathrm{j}^{\text {th }}{ }^{\text {th }}$ intervention group who belong to the strata defined by age groups and for both the baseline and end line surveys. The counts actually used in estimating the probabilities of selection exclude those sample young adults with missing age or who stated during the baseline survey that they would not like to be contacted for the endline survey. 


\section{APPENDIX C: COLLECTING COST DATA}

The intervention included three chronological phases: a planning phase, an implementation phase and a monitoring and service delivery phase. The costs associated with the planning phase included those of the planning meetings (including the facilitators' and participants' time and costs such as per diems) for designing the interventions as well as the formative research that informed the planning process.

The implementation phase included training (time of trainers and trainees to reach and attend training (except peer educators) and expenses incurred in holding training). The time of peer educators was excluded because they do not receive a salary from the ministries and are not paid while attending training, but the time of professionals was included because these individuals took time away from their regular jobs to attending training, and thus are being paid to attend the training sessions.

Service statistics collected by PATH were used to determine service delivery costs. For schools, this information included the number of sessions devoted to the life skills curriculum, the length of these sessions, the number of individual contacts with students, and an estimate of preparation time. For clinics, the intention was to record the number of contacts made for contraceptive and other reproductive health services, pre and postintervention in the experimental and control groups, then calculate the differences between experimental and the control groups in numbers of clients seeking services, and then multiply by the average length of a visit (using information gained through 'mystery client' visits by adolescents during the diagnostic study to determine time used for the intervention. Unlike the school-based activities, the assumption was that services were already being provided to adolescents and so it would be necessary to calculate pre-post differences. Activities undertaken by peer educators were not costed in the calculations because they are not salaried and so there is no cost to the Ministry of Health for their time. The resources used to monitor and supervise the interventions, including labour and transportation costs, were costed and included.

\section{Allocation of costs}

The planning costs were allocated to an experimental area and to an intervention activity using the time spent on planning for specific interventions. If a planning session covered multiple interventions, then costs were allocated assuming equal time spent for each intervention. In the case of training for a particular intervention, if trainees from both experimental areas attended the training, then costs were allocated according to the proportion of attendees from each area, if known. If not known, then costs were allocated equally to both areas.

\section{The special case of PATH personnel}

Two PATH staff members devoted significant amounts of time to the project and so a different methodology was used to allocate their costs. They were asked to complete a form that indicated how they allocated their time; however, as this was done retrospectively the distribution of these costs is an estimate. Their time was then distributed to the different phases of the intervention: planning, training, or monitoring/service delivery.

\section{Monetary and non-monetary costs}

Costs were also classified as monetary (those requiring an actual payment) and non-monetary (resources which had already been purchased but were redirected to the intervention). For example, if a consultant were hired to train teachers, then there would be a monetary 
payment. However, if a staff member from the Ministry of Health conducted the training and was not additionally compensated, then although there would be no monetary payment there would be an opportunity cost, as this person would need to take time away from other duties to conduct the training. For this reason, the time of participants at training sessions is included. Generally, non-monetary costs included trainer and facilitator time (with the exception of PATH trainers), while monetary costs included the cost of PATH personnel (for planning, training, and supervising) as well as expenses for allowances, communication, recruitment, supplies and transportation.

Allowances refer to per diems and out-of-pocket expenses that participants received for attending meetings or trainings, or to monitoring field activities. Communication refers to costs associated with faxes, telephone and other communication that occurred during the three phases of the project. Office/computer supplies refer to costs incurred and printing and paper as well as for computers. Participant recruitment refers to compensation paid to various individuals to encourage their participation at meetings to develop the intervention. Transportation refers to expenses for travel to meetings, to training sessions and to the field for monitoring. Labour (facilitator, trainer, attendee, religious leader) refers to those persons who participated in various activities.

\section{Problems Encountered During Data Collection and Analysis}

\section{General Issues}

- Costs were likely to be under-estimated because forms were not always completed for every meeting, training session, or service delivery activity.

- The purpose of a meeting or a training session was not always recorded, so that these costs had to be apportioned using allocation criteria.

- Monetary costs (including PATH time) were assigned to one of the phases of the project based on the date of the expenditure; thus, early expenditures were assigned to planning, those that occurred later were assigned to training, and those that came latest were assigned to service delivery and monitoring. Within each of the project's phases, monetary costs were allocated using information on non-monetary costs. For example, if non-monetary costs for a particular type of training were highest, then this type of training was assigned the highest proportion of monetary costs. In the case of peer educators, a monetary cost per peer educator trained was computed and assigned to each intervention based on the number trained. Supervision expenditures were assumed to be equal for each intervention and assigned accordingly.

\section{Service delivery and monitoring costs}

- Health-based intervention. The time spent on the new services in clinics was to be measured by determining the difference in the increase in the number of clinic visits in the experimental compared with the control clinics ([increase in number of youth served in experimental clinics - increase in number of youth served in control clinics] $x$ average time of a consultation). Unfortunately the data submitted were not complete, and no data were available in the control clinics for the pre-intervention period. Thus, it was decided to use the difference in the number of visits pre-post in the two experimental groups to calculate the change in the number of clinic visits in areas A and B. However, the results from this analysis suggest that there has been no change in the number of adolescents 
seeking clinic services and so the service delivery time of clinic providers was not included in the calculations.

- School-based intervention. The time teachers spent providing education and counselling on the life-skills curriculum was obtained from monthly reports that the teachers submitted to PATH. These reports focus on new activities (such as life-skills sessions) as well as existing activities that would be expected to change as the result of the interventions (for example, counselling of individual students). Unfortunately, reporting of events was somewhat sporadic and so the service delivery costs may be underestimated.

- Community-based intervention. These activities mainly involved meetings held by religious leaders or community development assistants. As with the school-based intervention, some of these meetings or other activities may not have been recorded on the record forms, and therefore these costs are likely under-reported. It is also important to note that the intensity of these activities appears to have varied between sites A and B, and while some of the difference may be real, some may be due to under-reporting of activities.

- Monitoring and supervision. Visits were made to schools, clinics and to community centres, and meetings were held to discuss progress and problems with the intervention activities. Unfortunately, information is not available on the specific activities conducted on each trip and it is likely that the number of meetings is under-counted. Given the limited information, some criteria were used to allocate costs. For example, since site B had three interventions and the most activities requiring supervisory time, it was allocated three-fifths of the monitoring costs.

The non-monetary costs for supervision and monitoring meetings held with peer educators had to be estimated, as these meetings were not entered into the database. These costs were included because although the time of peer educators was not included, the time of the facilitators attending these meetings did need to be included. An estimate was made that nine meetings were held with each group of peer educators (i.e. one every two months over the 18-month intervention period) and that each meeting lasted 5 hours. 


\section{APPENDIX D: TRENDS IN PROPORTIONS OF ADOLESCENTS EVER HAVING SEX, BY AGE}

Note: The numbers of sexually active adolescents for the ages $10-12$ years were too small to include in these analyses.

\section{Proportion of girls having sex by age}

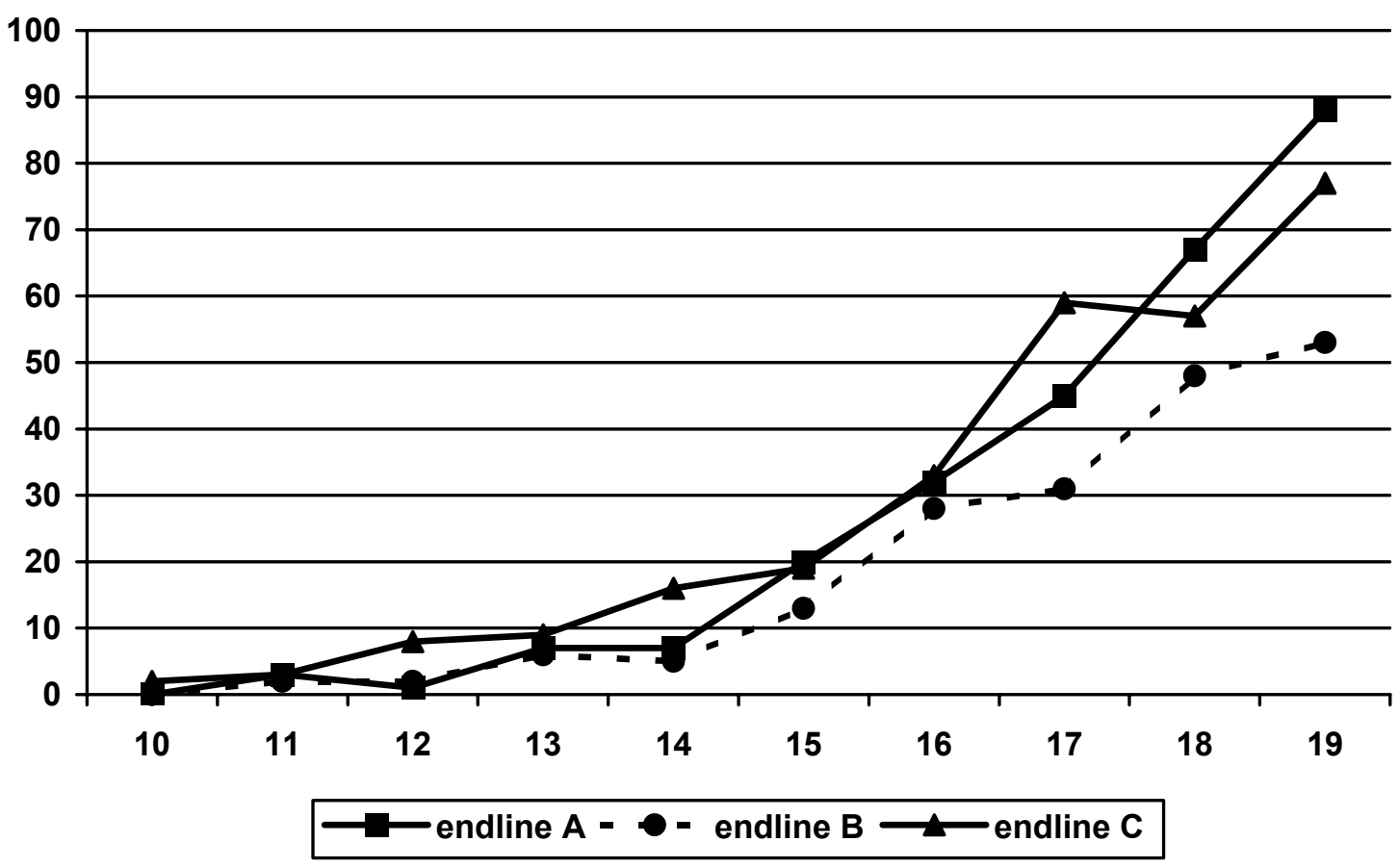

\section{Proportion of boys having sex by age}

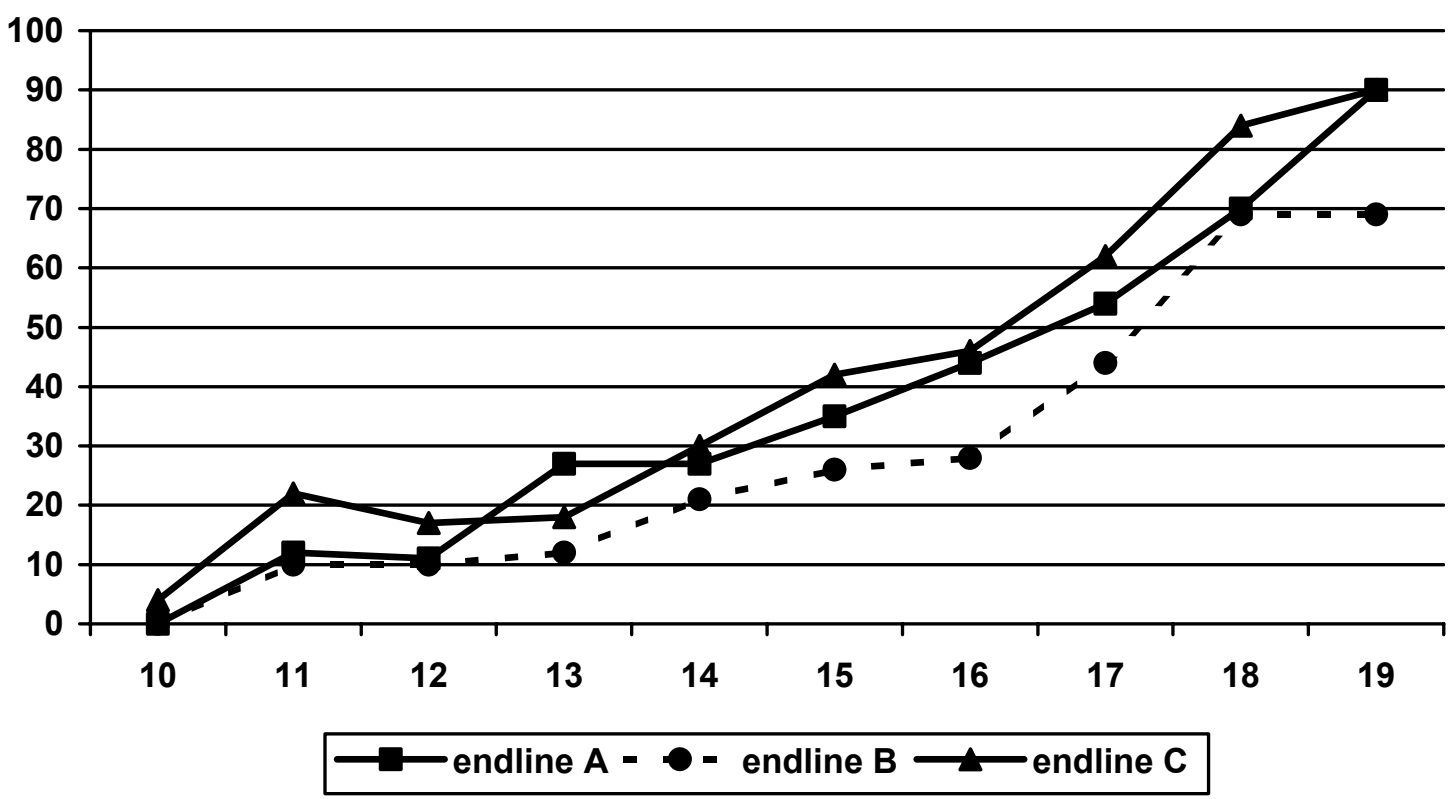

